\title{
Carotenoid biofortification in crop plants: citius, altius, fortius
}

\author{
Xiongjie Zheng ${ }^{1}$, Giovanni Guliano ${ }^{2}$, Salim Al-Babili ${ }^{1}$
}

${ }^{1}$ King Abdullah University of Science and Technology (KAUST), Division of Biological and Environmental Science and Engineering, Center for Desert Agriculture, the BioActives Lab, Thuwal 23955-6900, Saudi Arabia.

${ }^{2}$ Italian National Agency for New Technologies, Energy and Sustainable Economic Development (ENEA), Casaccia Research Center, Via Anguillarese 301, Roma 00123, Italy

Corresponding author: Salim Al-Babili (email: salim.babili@kaust.edu.sa)

\begin{abstract}
Carotenoids are indispensable for human health, required as precursors of vitamin A and efficient antioxidants. However, these plant pigments that play a vital role in photosynthesis are represented at insufficient levels in edible parts of several crops, which creates a need for increasing their content or optimizing their composition through biofortification. In particular, vitamin A deficiency, a severe health problem affecting the lives of millions in developing
\end{abstract}


countries, has triggered the development of a series of high-provitamin A crops, including Golden Rice as the best-known example. Further carotenoid-biofortified crops have been generated by using genetic engineering approaches or through classical breeding. In this review, we depict carotenoid metabolism in plants and provide an update on the development of carotenoid-biofortified plants and their potential to meet needs and expectations. Furthermore, we discuss the possibility of using natural variation for carotenoid biofortification and the potential of gene editing tools.

Key word: Carotenoids, Apocarotenoids, Vitamin A, Biofortification, Genetic engineering, Breeding, Gene editing

\section{Introduction}

Carotenoids are lipophilic isoprenoids synthesized by all photosynthetic organisms, including plants, algae and cyanobacteria, as well as by several non-photosynthetic fungi and prokaryotes [1-5]. Plant carotenoids consist of a common $\mathrm{C}_{40}$ backbone equipped with a conjugated system containing 3 to 11 double bonds that can assume different stereo-configurations. Carotenoids are divided into the oxygen-free carotenes and the oxygen-containing xanthophylls, and are further distinguished by the structure of their end groups. For non-biologists, carotenoids are best known for their bright colors that accumulate in many flowers and fruits to attract animals for pollination and seed dispersal, and also in many birds, fish and crustacean species [1, 6-9]. However, the essential need of plants and other photosynthetic organisms for carotenoids is explained by the vital role of these pigments in protecting the photosynthesis apparatus from photo-oxidation, which is brought about by quenching triplet state chlorophylls that can trigger the formation of singlet oxygen, a powerful Reacting Oxygen Species (ROS) that can oxidize 
and destroy chlorophylls and other cellular components. Besides preventing its formation, carotenoids scavenge this ROS by forming instable oxygen-containing epoxides and structures that also include other types of lipids [10]. In addition to photo protection, carotenoids contribute to photosynthesis as accessory light-harvesting pigments absorbing light in blue-green region and transferring the energy to chlorophylls [10]. Carotenoids are also the precursors of important plant hormones, i.e. abscisic acid [11] and strigolactones [12, 13], and of different signaling molecules [14, 15], such as $\beta$-cyclocitral [16, 17], zaxinone [18] and anchorene [19]. All of these carotenoid-derivatives are formed by oxidative cleavage of carotenoids, generally catalyzed by carotenoid cleavage dioxygenases (CCDs), a ubiquitous family of non-heme iron enzymes, found in bacteria, fungi, plants and animals [20-23]. Oxidative cleavage of carotenoids can be also mediated by lipoxygenases that use them as co-substrate [24, 25], or triggered non-enzymatically by $\operatorname{ROS}[16,26]$. For instance, chemical quenching of singlet oxygen in chloroplasts results in oxidative breakdown of $\beta$-carotene and the formation of the volatile signaling molecule and growth regulator $\beta$-cyclocitral $[16,17]$. Besides biosynthetic and storage capacities, degradation processes are a further determinant of carotenoid levels in plant tissues $[5]$.

In general, animals do not synthesize carotenoids de novo, but obtain them through their diet. In mammals, the enzyme $\beta$-carotene cleavage oxygenase 1 (BCO1), a member of the CCD enzyme family, catalyzes the first step in vitamin A (retinol) synthesis by forming retinal through the cleavage of the central $\mathrm{C} 15-\mathrm{C} 15$ 'double bond in $\beta$-carotene and other carotenoids containing a non-substituted $\beta$-ionone ring $[27,28]$. The contribution of carotenoids to vitamin A supply is particularly important if animal derived food is absent. In addition to their role as vitamin A precursors, carotenoids are required for human health as important antioxidants and ROS 
scavengers, preventing cancer, cardiovascular diseases and neurodegenerative disorders [29-33].

The non-provitamin A carotenoids zeaxanthin and lutein that accumulate in the macula are thought to alleviate and decrease the risk of age-related macular degeneration [32]. Moreover, lutein is the predominant carotenoid in the human brain tissue, and recent studies indicate a role of this carotenoid in brain development and cognitive performance throughout the lifespan [31, 34]. For instance, it has been shown that post-mortem brain lutein concentrations correlate with pre-mortem cognitive function [35]. Randomized supplementation clinical trial also suggested a positive impact of lutein on brain function and cognitive performance [36]. Though still disputed, the acyclic carotene lycopene has been implicated in preventing prostate cancer [33]. Several health benefits, including decreasing the risk of certain cancers and arteriosclerosis, have been suggested for the colorless, acyclic carotenes phytoene and phytofluene, which can be used as nutricosmetics to protect the skin from damage caused by free radicals [37-39]. Astaxanthin, a ketocarotenoid synthesized by algae and cyanobacteria, is an efficient antioxidant and a high-value feed additive used in aquaculture to obtain red/pink flesh color and enhance the immunity of farmed fish [40, 41]. Considering their various health benefits and attracting colors, carotenoids, mainly obtained through chemical synthesis, are used commercially as food and feed additives, as well as in the cosmetic industry [4, 42].

Vitamin A deficiency (VAD) is still one of the most severe global health problems. Thus, lack of this micronutrient is impacting over 125 million preschool-aged children and 7 million pregnant women in developing countries [43]. VAD is the major reason for childhood mortality, causing annually over 650000 early childhood deaths and preventable pediatric blindness [43]. Considering the severity of VAD and its fatal consequences, there have been large efforts to biofortify different crops with provitamin A carotenoids, mainly $\beta$-carotene, as a sustainable 
strategy to compensate the scarcity of animal-derived diet and combat VAD. These efforts led to the generation of Golden Rice, a milestone in plant metabolic/genetic engineering, and to many other "Golden Crops" with enhanced provitamin A content [44]. The demand for natural carotenoids as food and feed additives, and their versatile health benefits has also prompted the engineering of further carotenoid-biofortified crops, either by generally increasing carotenoid content (quantitative engineering) or by installing specific pathways from other organisms to produce new high-value carotenoid metabolites, e.g. astaxanthin and crocin, (qualitative engineering).

In this review, we provide an update on plant carotenoid metabolism and underlying regulatory processes, summarize the progress in generating and assessing the utility of carotenoid-biofortified crop plants, and discuss currently employed strategies. Finally, we touch on the potential of knowledge-based multiple gene engineering and gene editing in carotenoid biofortification.

\section{Carotenoid metabolism in plants}

Understanding biosynthetic pathways and the underlying regulation mechanisms is an essential prerequisite for efficient harnessing of plants metabolic capacities for biofortification. The plant carotenoid biosynthesis pathway has been almost completely elucidated, thanks to the efforts of many scientists in the field. However, our knowledge about the regulation of carotenogenesis is still limited.

\subsection{Biosynthesis of the isoprenoid building block}

Like other isoprenoids, carotenoids are formed from the universal $\mathrm{C}_{5}$ building block isopentenyl diphosphate (IPP) through condensation with its isomer dimethylallyl diphosphate (DMAPP) 
(Fig. 1). Higher plants and some algae are unique in having two different pathways for IPP biosynthesis [45]. The first one, the mevalonate pathway, provides the precursor for larger cytosolic isoprenoids, including sesquiterpenes, phytosterols, dolichols, triterpenes, and also isoprenoids for protein modification. The mevalonate pathway involves six enzymes and starts with the condensation of two acetyl-CoA molecules into acetoacetyl-CoA, which is catalyzed by the enzyme acetoacetyl-CoA thiolase (AACT) (Fig. 1). In the next step, the enzyme 3-hydroxy-3-methylglutaryl-coenzyme A synthase (HMGS) catalyzes a second condensation reaction with one acetyl-CoA unit, yielding HMG-CoA. The latter is then reduced by the enzyme HMG-CoA reductase (HMGR) to mevalonate (MVA), the substrate of the enzyme mevalonate kinase (MVK) that forms phosphomevalonate. A second phosphorylation reaction, catalyzed by the phosphomevalonate kinase (PMK), yields mevalonate 5-diphosphate (MVAPP). Finally, the diphosphomevalonate decarboxylase (MVD) mediates a reductive decarboxylation of MVAPP to form IPP. The enzyme isopentenyl diphosphate isomerase converts IPP into its isomer DMAPP. The mevalonate pathway is responsible for IPP formation in animals, fungi, archaebacteria and some gram-positive bacteria, such as enterococci and staphylococci, and is the main source for IPP in the cytosol of plants [45]. The second IPP synthesis route, the methylerythritol 4-phosphate (MEP) pathway, is common in plastids of higher plants and some algae, and is the sole source of IPP in most gram-negative bacteria, cyanobacteria and green algae [45]. The MEP pathway starts with the condensation of the glycolytic glyceraldehyde 3-phosphate (GA-3-P) and pyruvate (Fig. 1). This initial reaction yields 1-deoxy-D-xylulose 5-phosphate (DXP) and is catalyzed by the enzyme 1-deoxy-D-xxylulose 5-phosphate synthase (DXS). In the next step, the enzyme 1-deoxy-D-xylulose 5-phosphate reductoisomerase (DXR) mediates the reversible rearrangement of DXP into 2-C-methyl-D-erythritol 4-phosphate (MEP). The introduction of a 
cytidyl moiety, linked through a diphospho bridge, converts MEP into 4-(cytidine-diphospho)-2-C-methyl- $D$-erythritol (CDP-ME). CDP-ME is then phosphorylated by the enzyme 4-(cytidine 5'-diphospho)-2-C-methyl-D-erythritol kinase (CMK) to produce CDP-ME 2-phosphate (CDP-MEP). The latter reactions are catalyzed by the enzyme 2-C-methyl-D-erythritol 2, 4-cyclodiphosphate synthase (MDS) and yield 2-C-methyl-D-erythritol 2,4-cyclodiphosphate (MEcPP). Finally, IPP and DMAPP are formed through two sequential reduction reactions mediated by the enzymes (E)-4-hydroxy-3-methylbut-2-enyl diphosphate synthase (HDS) and reductase (HDR) [2, 46, 47].

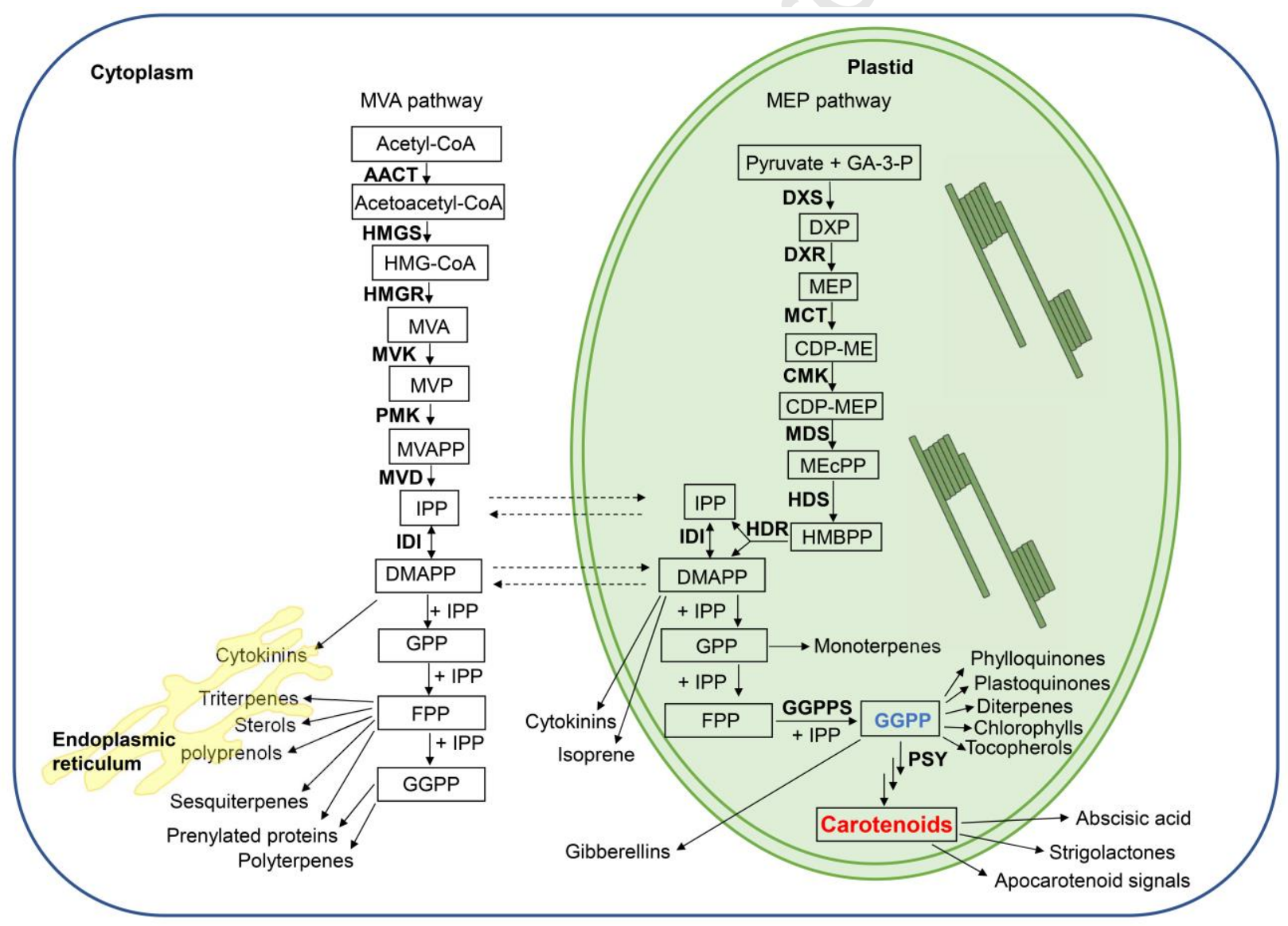

Figure 1. The MVA and MEP pathways in plants. Dashed arrows mark multiple steps of each pathways. Open arrows represent possible transport of IPP and DMAPP between plastids and cytoplasm. GA-3-P, glyceraldehyde 3-phosphate; DXP, 1-deoxy- $D$-xylulose 5'-phosphate; MEP, 2-C-methyl- $D$-erythritol 4-phosphate; CDP-ME, $\quad$ 4-(cytidine 5-diphospho)-2-C-methyl- $D$-erythritol; $\quad$ CDP-MEP， CDP-ME 2-phosphate; MEcPP, 
2-C-methyl-D-erythritol 2,4-cyclodiphosphate; HMBPP, 4-hydroxy-3-methylbut-2-enyl diphosphate; IPP, isopentenyl diphosphate; DMAPP, di-methylallyl diphosphate; GPP, geranyl diphosphate; FPP, farnesyl pyrophosphate; GGPP, geranylgeranyl diphosphate. HMG-CoA, 3-hydroxy-3-methylglutaryl CoA; MVA, mevalonic acid; MVP, 5-phosphomevalonate; MVAPP, 5-diphosphomevalonate. Enzymes of MEP pathway are indicated in bold: DXS, 1-Deoxy- $D$-xylulose 5-phosphate synthase; DXR, 1-Deoxy-D-xylulose 5-phosphate reductoisomerase; MCT, 2-C-methyl- $D$-erythritol 4-phosphate cytidyltransferase; CMK, 4-(cytidine 5'-diphospho)-2-C-methyl-D-erythtitol kinase; MDS, 2-C-methyl-D-erythritol 2,4-cyclodiphosphate synthase; HDS, HMBPP synthase; HDR, HMBPP reductase; IDI, isopentenyl diphosphate isomerase; GGDS, GGPP synthase; PSY, phytoene synthase. Enzymes of MVA pathway: AACT, acetoacetyl-CoA thiolase; HMGS, HMG-CoA synthase; HMGR, HMG-CoA reductase; MVK, MVA kinase; PMK, MVP kinase; MVD, MVPP decarboxylase;

Several lines of evidence suggest an exchange of isoprene building units (IPP and DMAPP) between plastids and cytoplasm (for review, see [48]). This exchange has been demonstrated by using specific inhibitors that target either the MEP or the MVA pathway [49, 50], by feeding with labeled precursors [51] and by analyzing genetic blocks in one of the two pathways [52]. However, this exchange is limited; and it can be assumed that the mevalonate pathway does not significantly contribute to carotenoid biosynthesis, as shown by the albino phenotype of mutants disrupted in the MEP pathway or treated with the DXR inhibitor fosmidomycin [48].

All enzymes of the MEP pathway are regulated at transcriptional level. In addition, it has been shown that the activity of the first enzyme in the pathway, DXS, which shows highest flux control coefficient in ${ }^{13} \mathrm{C}$ labeling experiments [53], and of DXR and HDS is also regulated at the translational and post-translational levels (reviewed in: $[54,55]$ ). Besides phosphorylation, the post-translational regulation of DXS activity includes reactivation or Clp-protease dependent degradation of misfolded enzyme, depending on the growth conditions [56-58]. The Clp protease system also regulates the activity of other enzymes in the MEP pathway [58, 59]. In addition, MEP pathway enzymes undergo redox regulation [54], possibly through the action of thioredoxin [60]. The MEP pathway is also regulated by the end products IPP and DMAPP that repress the 
activity of the key enzyme DXS $[61,62]$. The decrease in the levels of these end products leads to increased DXS protein levels [47].

\subsection{Biosynthesis of carotenes and xanthophylls}

The next step towards carotenoid biosynthesis is mediated by the enzyme geranylgeranyl diphosphate synthase (GGPS) that catalyzes the stepwise 1'-4 head-to-tail condensation of three IPP units and one DMAPP molecule to form the $\mathrm{C}_{20}$ metabolite geranylgeranyl diphosphate (GGPP; $\mathrm{C}_{20}$ ) via the intermediates GPP and farnesyl diphosphate (FPP) (Fig. 1). In addition to carotenoids, GGPP is the precursor of tocopherols, of the side chain of chlorophylls, phytol, of plastoquinones, and of the phytohormones gibberellins. Therefore, increasing carotenoid content may cause a shortage in GGPP supply, which negatively impacts the growth and development of the plant (s. below).

The first committed step in carotenogenesis is the head to head condensation of two $\mathrm{C}_{20}$ geranylgeranyl diphosphate (GGPP), which yields the colorless carotene 15-cis-phytoene $\left(\mathrm{C}_{40}\right)$ (Fig. 2). This reaction is catalyzed by the enzyme phytoene synthase (PSY), which is considered as the key enzyme in plant carotenoid biosynthesis and assumed to control the carotenoid metabolic pool size $[63,64]$. Transcript, protein abundance and activity change of PSY can dramatically affect metabolism flux to carotenoid; thus, it is an important target for elucidating the regulation of carotenoid biosynthesis and for increasing carotenoid content by metabolic engineering. A series of desaturation and isomerization reactions extends the carotene polyene from three to eleven double bonds, converting the colorless 15-cis-phytoene into the red all-trans-lycopene (Fig. 2). In plants and cyanobacteria, the formation of all-trans-lycopene through the poly-cis pathway requires four enzymes. The first one, phytoene desaturase (PDS), introduces, coupled with cis/trans-isomerization, two double bonds, leading to 9, 15, 


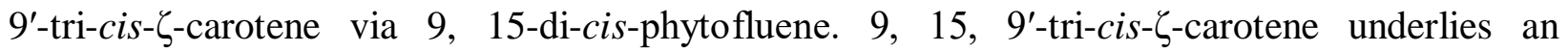
isomerization reaction catalyzed by the $\zeta$-carotene isomerase (Z-ISO) that changes the configuration of the central double bond to yield 9,9'-di-cis- $\zeta$-carotene (Fig. 2). The following two dehydrogenation reactions are catalyzed by the $\zeta$-carotene desaturase (ZDS) that forms 7,9 , 9', 7'-tetra-cis-lycopene (prolycopene) via 7, 9, 9'-tri-cis-neurosporene. The fourth enzyme, the carotene isomerase CRTISO converts prolycopene into all-trans-lycopene [65-68]. Remarkably, most of carotenogenic bacteria, with the exception of cyanobacteria, require only a single enzyme, CrtI, which carries out four desaturations and the required cis/trans-isomerizations, to form all-trans-lycopene from 15-cis-phytoene [69].

The reason why plants and cyanobacteria rely on the complex poly-cis pathway for all-trans-lycopene synthesis is still elusive. It is assumed that cis-configured lycopene precursors are a source of signaling molecules that regulate several aspects of plant development and the carotenoid biosynthesis itself $[5,70]$. The capability of CrtI in replacing four plant enzymes has made it an excellent tool for carotenoid biofortification. Thus, most of crops engineered for high carotenoid content contain bacterial CrtI, mainly from Pantoea agglomerans (formerly Erwinia herbicola) or Pantoea ananatis (formerly Erwinia uredovora), as a transgene. 


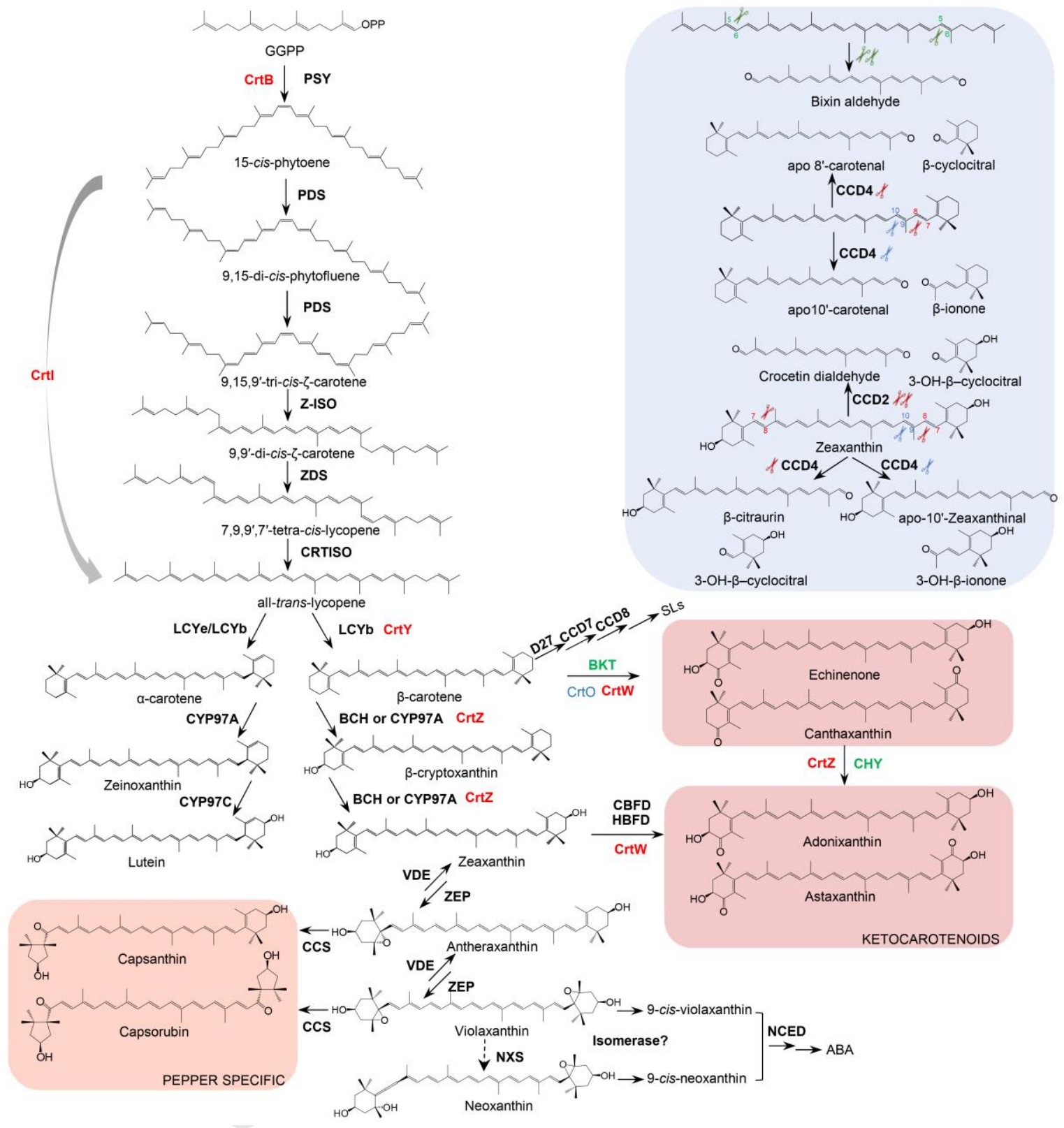

Figure 2. General carotenoid metabolic pathway in plant. Plant enzyme names are in black letters. GGPP, geranylgeranyl diphosphate; PSY, phytoene synthase; PDS, phytoene desaturase; Z-ISO, $\zeta$-carotene isomerase; ZDS, $\zeta$-carotene desaturase; CRTISO, carotenoid isomerase; LCYe, lycopene $\varepsilon$-cyclase; LCYb, lycopene $\beta$-cyclase; $\mathrm{BCH}, \beta$-carotene hydroxylase; CYP97A, cytochrome P450-type monooxygenase 97A (carotene $\beta$-hydroxylase); CYP97C, cytochrome P450-type monooxygenase 97C (carotene $\varepsilon$-hydroxylase); ZEP, zeaxanthin epoxidase; VDE, violaxanthin de-epoxidase. NXS, neoxanthin synthase. CCS, capsanthin-capsorubin synthase; D27, iron-containing carotenoid isomerase; CCD7, carotenoid cleavage dioxygenase 7; and CCD8, carotenoid cleavage dioxygenase 8. CCD4, carotenoid cleavage dioxygenase 4; CCD2, carotenoid cleavage dioxygenase 2; NCED, 9-cis-epoxycarotenoid dioxygenase. CCS, capsanthin-capsorubin synthase; CBFD, carotenoid $\beta$-ring 4-dehydrogenase; HBFD, 
4-hydroxy- $\beta$-ring 4-dehydrogenase. Bacterial enzyme names are in red letters, microalgal in green, cyanobacterial in blue. CrtB, bacterial phytoene synthase; CrtI, bacterial phytoene desaturase/isomerase; $\mathrm{CrtW}$, bacterial ketolase; CrtZ, bacterial hydroxylase; BKT, ketolase from green algae; $\mathrm{CHY}, \beta$-carotene hydroxylase from green algae; CrtO, cyanobacterial ketolase; ABA, abscisic acid; SLs, strigolactone.

Plant carotenoid biosynthesis bifurcates at the level of lycopene into two branches defined based on the type of introduced ionone ring (Fig. 2). The $\beta$-branch starts with the lycopene $\beta$-cyclase ( $\mathrm{LCYb}$ ) catalyzed reaction that converts the linear ends of lycopene into $\beta$-ionone rings, forming $\beta$-carotene. The first carotene in the second branch is $\alpha$-carotene that carries one $\beta$ - and one $\varepsilon$-ionone ring, which are formed by LCYb and lycopene $\varepsilon$-cyclase (LCYe) [71, 72]. Both cyclic carotenes are subjected to ring-specific hydroxylation reactions that convert $\beta$-carotene into zeaxanthin via the mono-hydroxylated $\beta$-cryptoxanthin, and $\alpha$-carotene into lutein (Fig. 2). The hydroxylation of $\beta$-carotene is mainly catalyzed by ferredoxin-dependent non-heme $\beta$-ring hydroxylases (BCH1 and $\mathrm{BCH} 2$ in Arabidopsis), which contain an iron-coordinating histidine cluster essential for activity [73-75]. In contrast, lutein biosynthesis requires two distinct hydroxylation reactions of the $\beta$ - and $\varepsilon$-rings, which are catalyzed by the cytochrome P450-type $\beta$-ring hydroxylase (CYP97A3) and $\varepsilon$-ring hydroxylase (CYP97C1) [76-78]. Zeaxanthin is the substrate for the zeaxanthin epoxidase (ZEP) that introduces an epoxy group in each of the $\beta$-ionone rings, forming violaxanthin via the monoepoxydated antheraxanthin (Fig. 2). The epoxidation reactions are reversible and constitute, together with the violaxanthin de-epoxidase (VDE) catalyzed de-epoxidation steps, the xanthophyll cycle that determines - depending on light intensity - the content of the photoprotective zeaxanthin [79]. The final step in the core biosynthetic pathway of plant carotenoids is the introduction of an allenic double bound in violaxanthin, which is catalyzed by a presumed neoxanthin synthase (NXS) and leads to 
neoxanthin [5]. However, the identity of the neoxanthin synthesizing enzyme remains elusive, as neoxanthin-deficient mutants reported so far, i.e. the Arabidopsis aba4 and the tomato $n x d 1$, are affected in genes that are required but not sufficient for neoxanthin production [80, 81].

In addition to the above depicted common plant carotenoid pathway, there are several species-specific carotenoid biosynthesis pathways, which occur in certain organs and expand the structural diversity of carotenoids. A well-known example is the formation of the $\beta$-ring xanthophylls capsanthin and capsorubin from antheraxanthin and violaxanthin, respectively (Fig. 2). The enzyme, capsanthin-capsorubin synthase (CCS), catalyzing this reaction is a homolog of the lycopene cyclizing enzyme $\operatorname{LCYb}[6,82]$. Flowers of the ornamental and medicinal plant Adonis aestivalis, accumulate astaxanthin that is usually present in algae and some cyanobacteria. The synthesis of this ketocarotenoid (3,3'-dihydroxy- $\beta, \beta$-carotene-4,4'-dione) likely proceeds via 4-hydroxy- $\beta$-ionone ring intermediates and is catalyzed by the sequential action of the two enzymes carotenoid $\beta$-ring 4-dehydrogenase (CBFD) and 4-hydroxy- $\beta$-ring 4-dehydrogenase (HBFD) (Fig. 2) [83]. The first step of astaxanthin biosynthesis in green algae, such as Haematococcus pluvialis the richest natural source of this carotenoid, is catalyzed by the $\beta$-carotene ketolase (BKT) that introduces a keto group at the $\mathrm{C} 4$ and $\mathrm{C} 4$ ' position, forming canthaxanthin via the mono-keto carotenoid echinenone, followed by the hydroxylase (CHY) mediated hydroxylation at $\mathrm{C} 3$ and $\mathrm{C}^{\prime}$ ' position [84]. In marine bacteria, 4, 4' carotenoid oxygenase $(\mathrm{CrtW})$ can introduce keto groups at the $\mathrm{C} 4$ and $\mathrm{C} 4$ ' position of the carotenoid $\beta$ ionone rings with and without hydroxylation at the $3,3^{\prime}$ position [85]. CrtO is a cyanobacterial ketolase which acts asymmetrically to introduce a 4-keto group in the carotenoid $\beta$-ionone rings [2].

\subsection{Carotenoid storage, sequestration and further metabolism}


Plants contain different types of plastids that determine the level and pattern of carotenoids in a plant cell $[64,86]$. Photosynthetically active plastids, i.e. chloroplasts, have defined carotenoid composition that enables proper running of photosynthesis. In these plastids, carotenoids are composed of around $45 \%$ lutein, $25-30 \% \beta$-carotene, and $10-15 \%$ each of violaxanthin and neoxanthin. Other types of plastids show large variations in the amount and pattern of accumulated carotenoids. Leucoplasts, for instance, contain only small amounts of carotenoids with significantly higher ration of $\beta$-ionone ring containing xanthophylls $[87,88]$. To confer intense colors to flowers, fruits and other organs, plants develop a specialized type of plastids, the chromoplasts, which accumulate high levels of certain carotenoids, such as lutein in daffodil flowers or lycopene in tomato fruits. Chromoplasts can originate from proplastids, chloroplasts or the starch storing amyloplasts, and are characterized by an intensive biosynthesis of carotenoids and other structural components, such as multi-layer membrane structures, lipoproteins or fibrils, which stabilize and accommodate high carotenoid concentrations [89]. These structures sequester newly synthesized carotenoids, preventing overloading the site of synthesis with end products and enabling stable storage [89]. Therefore, triggering the formation of chromoplasts may be a very fruitful approach for carotenoid-biofortification. However, our knowledge about the genetic control of chromoplast biogenesis is limited. The ORANGE (Or) gene is able to induce chromoplast differentiation in different plant species, including cauliflower, melon fruit and potato tuber [90-92]. The Or gene encodes a protein with Cys-rich zinc finger domain found in DnaJ co-chaperones and was originally discovered in a semi-dominant cauliflower mutant that accumulates $\beta$-carotene in its curds in heterozygous state without showing an increase in the transcript levels of carotenoid biosynthesis enzymes [90, 93, 94]. It is likely that Or acts through at least two different mechanisms to increase carotenoid content: 
Wild-type Or isoform enhances the stability of PSY, the key enzyme in carotenogenesis, leading to an increase in its activity and, hence, in total carotenoid content, while the Arg > His isoform reduces $\beta$-carotene degradation [92, 95, 96]. Or plays also a crucial role in chromoplast biogenesis, as shown by genetic analysis of the or cauliflower and orange flesh melon mutants and by the ability of 'Golden SNP' containing $O r$ in triggering chromoplast formation [90-92]. This role is further supported by inducing chromoplast formation in Arabidopsis callus and potato tubers upon ectopic expression of the $\operatorname{Or}$ gene [97, 98].

Overexpression of plant or bacterial phytoene synthase genes is able to trigger the formation of chromoplast-like structures accumulating large amounts of intra-plastidial carotenoids $[88,99$, 100]. Transcriptome analyses indicate that this process closely resembles chloroplast to chromoplast transition in tomato fruits [100]. The application of Occam's razor suggests that chromoplast differentiation triggered by $O r$ and $P S Y$ overexpression are mechanistically related, and that they are triggered by the high carotenoid levels accumulated within the plastid.

The presence of an extended, conjugated double bond system in carotenoids makes them prone to degradation caused by oxidative cleavage. This process takes continuously place in chloroplasts, particularly under high illumination rate that increases ROS formation, leading to a wide range of oxidation products that are subjected to hydroxylation and further modified to apocarotenoid glycosides [101-103]. Some products of this oxidative degradation are perceived, with or without modification, in the cell as signaling molecules modulating gene transcription, as shown for $\beta$-cyclocitral that also acts as a root growth regulator $[16,17]$. It can be assumed that carotenoid degradation is compensated by an active biosynthesis pathway that maintains the rigorous stoichiometry between chlorophylls, carotenoids and structural proteins, which is required for smooth functioning of photosynthesis and ensures sufficient supply for the synthesis 
of carotenoid-derived signaling molecules and hormones. Conversion of carotenoids into apocarotenoid glycosides is also used to maintain carotenoid homeostasis in chloroplasts of PSY overexpressing plants [103].

Xanthophyll esterification with fatty acids is a widespread mechanism for carotenoid sequestration that allows accumulation of carotenoids and improves their stability. In tomato, map-based positional cloning identified a carotenoid-modifying gene PYP1 (Pale Yellow Petal 1) that is required for violaxanthin and neoxanthin esterification in flowers. PYPl encodes an acyltransferase-related protein and mutations of the gene result in loss of xanthophyll esters, decreased xanthophyll accumulation and altered chromoplast development [104]. The enzymatic function of PYP1 has not been demonstrated. However, expression of a pepper homolog of PYP1 correlates with accumulation of esterified xanthophylls in pepper fruits [105].

In bread wheat, xanthophylls are esterified, and a major locus called Lute, located on the D genome, controls xanthophyll esterification. Lute encodes a GDSL-like lipase able to catalyze transesterification of xanthophylls. Interestingly, the protein shows an apoplastic, rather than plastid localization, prompting speculation that it acts on xanthophylls released from the plastid during seed maturation [106-108]. Very little is known about the mechanisms (if any) through which carotenoids are transported within and between cells. It is notable that some CCDs have a cytoplasmic localization, therefore it can be assumed that their carotenoid and/or apocarotenoid substrates must leave the plastid, or at least be exposed on its surface, to become accessible. Much more is known about the mechanisms mediating the inter- and intra-cellular transport of apocarotenoids. ABA transport and vacuolar sequestration is mediated by ATP-Binding Cassette (ABC) and Multidrug and Toxic compound Extrusion (MATE) transporters [109-112]. 
Strigolactone translocation in petunia and vacuolar sequestration of crocins in saffron are mediated by $\mathrm{ABC}$ transporters $[113,114]$.

\subsection{Carotenoid cleavage}

Beside non-enzymatic degradation processes [16, 115], plant carotenoids are subjected to enzymatic cleavage reactions that play a significant role in determining carotenoid content and initiate anabolic pathways forming various hormones/signaling molecules, novel pigments, and volatile/flavor compounds. Lipoxygenases (LOXs), enzymes catalyzing the peroxidation of polyunsaturated fatty acids, such as linoleic, linolenic and arachidonic acid, form fatty acid peroxyl radical intermediates that can attack and degrade carotenoids in vitro [116]. Fortification of wheat flour with lipoxygenase-containing soybean flour increases protein content, improves the rheological properties of the resulting dough, and bleaches carotenoids for obtaining white bread $[24,25]$. A deletion at the Lpx-B1 locus of durum wheat is associated with greater carotenoid stability during pasta making, while RNAi-mediated down-regulation of lipoxygenase activity improves carotenoid stability during storage of Golden Rice [117, 118]. Recently, a comparative genomic study has provided genetic evidence for the role of tomato LoxC in producing the carotene-derived volatiles $\beta$-cyclocitral and $\beta$-ionone [119].

The enzymology and biology of CCDs have been extensively studied in the last years. These enzymes constitute a ubiquitous family present in bacteria, fungi, plants and animals [21, 23, 120]. Vertebrates contain three members of the $\mathrm{CCD}$ family: (i): the $\beta$-carotene 15,15'-monooxygenase (BCO1) [121, 122], which plays a key role in retinol (vitamin A) synthesis, by catalyzing symmetrical cleavage of carotenoids at the central 15,15 ' double bond, and (ii) the (BCO2) that catalyzes the asymmetrical cleavage of carotenoids and is thought to determine carotenoid homeostasis $[121,122]$, and (iii) the Retinal pigment epithelium-specific 
$65 \mathrm{kDa}$ protein (RPE65) a retinoid isomerohydrolase required for the vision cycle [123]. Plants contain diverse types of CCDs. For instance, there are nine $C C D$ genes in the model plant Arabidopsis thaliana. Five of them encode 9-cis-epoxycarotenoid dioxygenases (NCEDs: NCED2, NCED3, NCED5, NCED6 and NCED9) that form the abscisic acid precursor xanthoxin $[11-13,124]$. The other four encodes enzymes designated as CCD1, CCD4, CCD7 and CCD8, which have different cleavage activities and biological functions [13, 14]. Arabidopsis CCD1, as well as its orthologs from other plant species, are characterized by relaxed substrate and double bond specificity. In vitro enzymatic studies have shown that CCD1 enzymes cleave several carotenoids and apocarotenoid substrates at different double bonds in carotenoids backbone [125-128]. This activity gives rise to many volatile compounds that contribute to the aroma and flavor of fruits and flowers, and to dialdehydes with different chain lengths $[125,126]$. The role of CCD1 in the formation of carotenoid-derived volatiles has been confirmed using mutants and RNAi approaches [129-131]. CCD2, a close CCD1 relative common in Crocus species cleaves the (C7-C8) and (C7'-C8') double bounds, converting zeaxanthin into crocetin dialdehyde and 3-hydroxy- $\beta$-cyclocitral (Fig. 2) [132, 133]. Crocetin dialdehyde is the precursor of crocins and 3-hydroxy- $\beta$-cyclocitral is the indirect precursor of picrocrocin which are responsible for the color and flavor of saffron, respectively $[134,135]$.

CCD4 is a further CCD that contributes to the production of volatile compounds. The Arabidopsis CCD4 cleaves the (C9-C10) double bond in bicyclic carotenoids, yielding $\beta$-apo-10'-carotenoids and $\mathrm{C}_{13}$-volatiles (Fig. 2) [136]. This cleavage activity leads to the conversion of carotenoids into color-less metabolites [137] and has been also reported for the potato CCD4 [138]. However, there is a second type of CCD4 enzymes, which cleaves the (C7-C8) double bond in bicyclic carotenoids, including $\beta$-carotene, $\beta$-cryptoxanthin and 
zeaxanthin, as shown for Citrus $\mathrm{CCD} 4 \mathrm{~b}$ that forms the citrus pigments $\beta$-citraurin and $\beta$-citraurinene (Fig. 2) [137, 139-142]. Other forms of CCD4 enzymes catalyze double cleavage of carotenoids. The Buddleja davidii CCD4 enzymes BdCCD4.1 and BdCCD4.3 cleave zeaxanthin at the $\mathrm{C} 7-\mathrm{C} 8$ and $\mathrm{C}^{\prime}{ }^{\prime}-\mathrm{C} 8^{\prime}$ double bonds, producing crocetin dialdehyde and 3-hydroxy- $\beta$-cyclocitral [143]. CCD7 and CCD8, are strigolactone biosynthesis enzymes that act sequentially to form the SL precursor carlactone (Fig. 2) [144]. The stereospecific CCD7 cleaves 9-cis- $\beta$-carotene provided by the carotene isomerase DWARF27 at the (C9'-C10') double bound to produce 9-cis- $\beta$-apo-10'-carotenal and $\beta$-ionone [144-147]. In the next step, 9-cis- $\beta$-apo-10'-carotenal is converted by CCD8 into carlactone [144]. It is assumed that CCD8 catalyzes a combination of different reactions, including isomerization, intramolecular rearrangement and repeated oxygenation, when exposed to the 9-cis- $\beta$-apo-10'-carotenal [148]. Remarkably, CCD8 enzymes mediate a common double bond cleavage reaction with all-trans- $\beta$-apo-10'-carotenal, which leads to the ketone $\beta$-apo-13-carotenone $[144,149]$. Conversion of carlactone by CYP450 enzymes (711A1 clade) gives rise to different SLs [150, 151].

There are CCD types other than those present in Arabidopsis. In addition to the aforementioned CCD2, Zaxinone synthase (ZAS) represents a common CCD subfamily that has been recently unraveled by analyzing CCD genes from 69 plant species $[14,15,18]$. The rice zaxinone synthase (ZAS) cleaves the apocarotenoid all-trans-3-OH-apo-10'-carotenal (all-trans-apo-10'-zeaxanthinal) at the $\mathrm{C} 13-\mathrm{C} 14$ double bond, forming the $\mathrm{C}_{18}$-ketone all-trans-apo-13-zeaxanthinone that was called for simplicity zaxinone [18]. Analysis of the rice zas mutant and exogenous application of zaxinone suggest that this apocarotenoid is a novel growth regulator required for normal rice growth and a plant hormone candidate [18]. 
The negative impact of CCD activity on carotenoid content has been demonstrated for CCD4 enzymes in different tissues, including potato tubers, chrysanthemum and brassica species flowers, peach fruits, Arabidopsis seeds [152-158], and very recently in Japanese morning glory (Ipomoea nil) petals [159]. A recent study suggests that the Arabidopsis CCD4 is degraded by a plastoglobule-localized metallopeptidase PGM48, and that PGM48 overexpression leads to a dramatically reduced level of CCD4 protein [160]. However, it remains to be answered whether PGM48 is a positive regulator of carotenoid content. CCD1 enzymes seem to have less impact on carotenoid content [154] and are thought to cleave already destructed carotenoids, i.e. apocarotenoids, rather than carotenoids in planta $[125,161]$. Indeed, overexpression of rice CCD1 in Golden Rice endosperm did not significantly affect carotenoid content [161]. Considering that the products of NCEDs and CCD7/CCD8 are hormone precursors occurring at low concentrations, it can be assumed that the activity of these enzymes does not play a major role in determining total carotenoid content. Nevertheless, the upregulation of PSY3 transcript levels in response to stimuli increasing $\mathrm{ABA}$ level in cereal roots indicates that precursor availability is a limiting factor in ABA biosynthesis and points to NCED activity as a determinant of carotenoid content in this tissue $[162,163]$.

\subsection{Regulation of carotenogenesis}

Plant carotenoid biosynthesis is regulated at different levels, including transcriptional, post-translational and end product mediated feedback regulation $[5,89,164]$. In general, factors regulating transcript levels differ between green and non-photosynthetic tissues [165]. In photosynthetic tissues, the Arabidopsis Phytochrome Interacting Factor 1 (PIF1) and bZIP transcription factor Long Hypocotyl 5 (HY5) are perhaps the best understood transcriptional regulators of the carotenoid pathway. Both HY5 (activator) and PIFs (repressors) can directly 
interact with same G-box motif located in the PSY promoter, which constitutes a dynamic activation-repression module that responds to temperature and light cues [166]. The Arabidopsis RAP2.2 was shown to bind the $P S Y$ and $P D S$ promoters in vitro [167], however, its precise role in regulating carotenoid biosynthesis remains elusive.

Several known transcriptional regulators have been shown to control carotenoid biosynthesis in fruits, especially in the model species tomato. For example, some MADS-box proteins, such as tomato Ripening Inhibitor (RIN), AGAMOUS-LIKE1 (TAGL1), FRUITFULL1 (FUL1), and FUL2, have been shown to positively regulate the transcript levels of PSY, ZDS, Z-ISO, CRTISO, and $B C H$ genes, while repressing the transcripts of lycopene cyclases, i.e LCYb, CYCB (fruit-specific LCYb) and LCYe [165]. During tomato fruit development, carotenoid biosynthesis is also regulated by factors involved in hormone biogenesis and light signaling. For example, the NAC4 transcription factor involved in the regulation of ethylene biosynthesis acts also as a positive regulator of PSY1 and a suppressor of the expression of $L C Y b, C Y C B$ and $L C Y e$ [168].NAC1, a further NAC family member, showed the opposite effect [169, 170]. Several regulatory factors exert their effect by direct interaction with carotenoid gene promoters: the MADS box transcription factor RIN binds directly to the promoter of PSYI, Z-ISO and CrtISO of tomato, inducing the transcription of the downstream genes [171]. The tomato B-box protein BBX20 binds a G-box in the PSY1 promoter to induce its expression [172], while the kiwifruit transcription factor AdMYB7 can directly bind to the $A d L C Y b$ promoter in vitro [173]. Overexpression of AdMYB7 in tobacco leaves enhanced the expression of $N b P S Y, N b P D S$, $N b Z D S, N b L C Y b$, and $N b L C Y e$ genes [173]. The citrus MADS6 transcription factor is a positive regulator of carotenoid biosynthesis, which directly interacts with promoter of CsPSY, CsPDS and CsLCYb1, thus providing a target for multigene manipulation [174]. PSY and PDS 
expression has been shown to be regulated by a feedback loop mediated by end products and/or cis-intermediates of the carotenoid pathway in carrot and tomato [70, 175, 176].

Several lines of evidence suggest that the expression of carotenoid biosynthesis genes is also regulated at epigenetic level. For example, it has been shown that a histone methyltransferase SDG8 (chromatin-modifying enzyme SET DOMAIN GROUP 8) is responsible for maintaining permissive histone methylation surrounding the promoter of CRTISO gene, and affects the level of the corresponding transcript in Arabidopsis [177]. Accordingly, disruption the SDG8 gene led a reduction in CRTISO mRNA level [177]. In addition to transcriptional regulation, post-translational control of enzyme activity and abundance is a further factor that determines carotenogenesis. As indicated above, the Or chaperone protein, the major post-translational regulator of PSY, has been shown to trigger carotenoid biosynthesis by increasing the stability of PSY $[92,95]$. In a recent study, it was demonstrated that PSY protein homeostasis is maintained through the opposite effects of the Clp-protease (CLP) degrading activity and the Or protein that increases the stability of this enzyme, which represents a new post-translational regulatory mechanism of plant carotenoid biosynthesis [178].

\section{Exploiting natural variation for carotenoid biofortification}

Forward genetics allows the identification of novel genetic factors underlying the phenotype of interest and opens up possibilities for developing new biofortified varieties, by using modern molecular breeding tools, such as Marker Assisted Selection (MAS) and Targeting Induced Local Lesions in Genomes (TILLING). In addition, this approach provides novel targets for metabolic engineering [179-181]. There is a large natural variation in carotenoid content and composition in several crop plants, which is caused by the presence of various alleles in structural carotenoid biosynthesis genes following simple Mendelian inheritance (major quantitative trait loci (QTLs), 
or by multiple minor QTLs. Maize endosperm carotenoid content is determined by major and minor QTLs. The first group maps to carotenoid biosynthesis genes PSY1, LCYe, ZDS and CHY1 [182-184]. $\mathrm{LCYe}$ and $B C H$ alleles causing increased $\beta$-carotene content are recessive, which can be explained by loss-of-function of the corresponding genes $[182,183]$. The negative impact of LCYe and CHY1 ( $\beta$-carotene hydroxylase 1) on $\beta$-carotene content is consistent with their enzymatic activity: LCYe diverts the precursor lycopene into the competing $\alpha$-branch while CHY1 converts $\beta$-carotene into xanthophylls. The two QTLs corresponding to LCYe and CHY1 were used for breeding of provitamin A biofortified maize hybrids through MAS [185]. In cassava, the allelic variation (Ala > Asp mutation) in PSY leads to enhanced enzymatic activity and, hence, to increased carotenoid accumulation in yellow-rooted cassava varieties with increased provitamin A content [186]. Recently, examination of two tomato PSY isoforms (PSY1 and PSY2) identified a neighboring aromatic-aromatic combination in their core structure, which is conserved in PSY enzymes from different species but absent in the fruit specific and enzymatically less efficient PSY1 [187]. Activity studies and site directed mutagenesis confirmed the role of this structural element [187]. Additional amino acid differences were found to be responsible for large differences in the activities of the daffodil and maize PSY enzymes, used to engineer "Golden rice" plants with different provitamin A contents [187, 188]. The identification of highly-efficient PSY alleles paves the way for generating them in other tissues or plant species by employing modern gene editing tools, such as CRISPR mediated targeted base editing [189].

The commonly grown orange carrots are characterized by extremely high levels of $\beta$ - and $\alpha$-carotene [190]. Two major recessive loci, Y1 and Y2, are responsible for the color of orange carrot genotypes that are yy $y 2 y 2$ [191]. The $Y 1$ locus has been shown to encode a putative 
repressor of photomorphogenesis. The corresponding recessive, loss-of-function allele $(y 1)$ is supposed to allow root carotenoid production even in the absence of light, while the identity of $Y 2$ is still elusive [192]. In addition, orange carrot genotypes are disrupted in the CYP97A3 gene responsible for $\beta$-ring hydroxylation in $\alpha$-carotene, which results in high accumulation of $\alpha$-carotene in both leaves and roots [175]. Complementation of orange carrot with Arabidopsis CYP97A3 gene led to a decrease of $\alpha$-carotene content in leaves and roots, accompanied by reduction of root $\beta$-carotene and total carotenoid level, which confirms the contribution of CYP97A3 to carrot color [175]. Recently, association analysis of domesticated and wild carrot accessions showed that a nonsynonymous mutation in $\mathrm{Or}$ gene is associated with carotenoid presence in domesticated carrots, indicating that the $O r$ gene may play a role in the emergence of carotenoid-accumulating carrot roots [193]. Genetic variation in ZEP is also coupled with variation in total carotenoid content. Retrotransposon insertion in the first potato ZEP intron reduces ZEP expression and causes an enhancement in total carotenoid content [194]. Recently, it was also shown that $Z E P$ is a major genetic determinant of carotenoid content and composition in Arabidopsis seeds and that mutants disrupted in ZEP have a 6-fold higher carotenoid content, suggesting that epoxidation of carotenoids makes them more accessible to degradation [195]. Variations in $C C D$ gene loci contribute to differences in carotenoid and apocarotenoid content among varieties of the same species, as shown for petals in different Brassica species [156, 157]. The role of CCD4 determining carotenoid content has been also demonstrated for Arabidopsis seeds, peach fruit flesh and potato tubers [152-154]. Consistently, CRISPR/Cas9-mediated disruption of $C C D 4$ resulted in a remarkable increase of carotenoids and flower color in Ipomoea nil [159]. In contrast to these examples, citrus $\mathrm{CCD} 4$, which forms red $\mathrm{C}_{30}$ apocarotenoid pigments by cleaving the $\mathrm{C} 7-\mathrm{C} 8$ double instead of the $\mathrm{C} 9-\mathrm{C} 10$ double bond targeted by 
Arabidopsis CCD4 [136, 137], is a positive regulator on citrus peel color [139, 140, 142]. Very recently, mQTL analysis of $\mathrm{C}_{30}$ apocarotenoid pigments showed that natural variation in $\mathrm{CCD} 4 \mathrm{~b}$ cis-regulatory region is a major genetic determinant of the content of $\beta$-citraurin and $\beta$-citraurinene, $\mathrm{C}_{30}$-apocarotenoid pigments, in different citrus varieties [141].

The Arg > His mutation found in the melon Or gene, designated as "Golden" SNP has been shown to be responsible for high $\beta$-carotene level and orange phenotype of fruits [91]. Precise gene editing tools will allow the introduction of the "Golden" SNP in other crops, which may lead to a set of novel biofortified plants. Very recently, CRISPR/Cas9-mediated modification of rice $O r$, which mimics the cauliflower mutation, resulted in producing orange-colored rice callus with $\beta$-carotene hyper-accumulation [196].

In plants showing little genetic variation for $\beta$-carotene content, induced mutations can be a viable alternative to transgenic approaches. Recently, a TILLING approach has been used to knock down the expression of the two LCYe homeologous genes in durum wheat [197]. In spite of a slight increase of $\mathrm{CHY}$ expression, the levels of two of provitamin A carotenoids ( $\beta$-carotene and $\beta$-cryptoxanthin) showed a slight increase in grains, while $\alpha$-branch carotenoids ( $\alpha$-carotene and lutein) disappeared completely.

\section{Metabolic engineering strategies for carotenoid biofortification in crop}

\section{plants}

The occurrence of accessions and varieties with diverse carotenoid content and compositions in crops, such as cauliflower, cassava, and corn, allows the employment of the biofortification concept by using conventional breeding. However, breeding is still a slow and laborious process, and not applicable if natural variation in carotenoid content is insufficient or, as it is the case with 
rice endosperm, even not present. Therefore, there has been a need for alternative genetic engineering approaches for carotenoid biofortification. Indeed, metabolic engineering has been in the last decades widely and successfully employed to generate crops with increased or modified carotenoid content (Table 1). Figure. 2 depicts the pathway steps that have been engineered by using plant and/or non-plant enzymes and the target crops. Metabolic engineering of carotenoids has been pursuing following strategies: a) increasing carotenoid production by overexpressing one or more biosynthetic enzymes; b) reducing further metabolization of the target carotenoid or the metabolic flux into a competing metabolic branch through gene silencing; c) increasing the "carotenoid sink" by providing additional sequestering capacities for carotenoid storage and d) enhancing the stability of formed carotenoids.

The strategy of enhancing the metabolic flux into carotenoid pathway by over-expressing genes encoding "rate-limiting" enzymes, in particular PSY, has been frequently used to produce high-carotenoid crops. Indeed, there are several examples for increasing the content of $\beta$-carotene and/or other carotenoids in various plant tissues, such as rice endosperm, tomato and banana fruits by using the "simple" approach of constitutive overexpression of a PSY gene from the same or different plant species [198-200]. Constitutive overexpression of Arabidopsis PDS gene also effectively enhanced carotenoids accumulation in tomato fruit [201]. However, constitutive overexpression of carotenogenic enzymes can cause unwanted pleiotropic developmental effects, such as dwarfism, loss of vigor and senescence [202-205]. These developmental phenotypes are likely the result of competition between metabolic routes and of alterations in the content of plant hormones, particularly gibberellins, which derive from carotenoids or their isoprenoid precursors. Negative pleiotropic effects coupled with overexpressing carotenoid biosynthesis enzymes may be avoided by employing tissue specific 
promoters, e.g. fruit-, tuber- or endosperm-specific promoters. It is also recommended to use genes from a different plant species or bacterial ones to circumvent co-suppression. For instance, overexpression of the bacterial phytoene synthase $C r t B$ driven by a fruit-specific promoter increased fruit total carotenoid content without significant alteration of other related isoprenoid pathways [63], in contrast to constitutive expression of the tomato fruit specific PSY1 [199]. Carotenoid engineering can also have positive pleiotropic effects. Constitutive overexpression of CHY in transgenic Arabidopsis and tobacco results in increased the tolerance to light and/or drought stress $[206,207]$. Constitutive overexpression of $L C Y b$ in tomato results in virtually complete lycopene conversion into $\beta$-carotene in the fruit and in higher fruit productivity per plant [208]. Fruit-specific overexpression of the same gene results in increased content of $\beta$-carotene and of its downstream metabolite, ABA, in decreased ethylene production, and in increased cuticle thickness and fruit shelf-life [209]. Shelf life extension has been also observed in cassava roots with increased carotenoid content, which showed reduced post-harvest deterioration [210].

Seed-specific overexpression of bacterial CrtB in Canola (Brassica napus) seeds, using the napin promoter, resulted in 50-fold increase of carotenoids, predominantly $\beta$ - and $\alpha$-carotene, which was, however, accompanied by a significant decrease in tocopherol levels and alterations in fatty acid composition [211]. Very recently, 'Golden' cotton seeds with around 6-fold increase in oil $\beta$-carotene content were generated by expressing a cotton phytoene synthase gene driven by a seed-specific promoter [212]. It has been also shown that elevating the plastid isoprenoid production upstream of the carotenoid pathway can be sufficient to enhance carotenoid content. For example, the overexpression of a bacterial $D X S$, a key enzyme in plastid IPP biosynthesis, results in modest increase in the carotenoid content of tomato fruits and potato tubers [213, 214]. 
Often, overexpression of a single biosynthetic gene is not sufficient to achieve the desired accumulation of $\beta$-carotene or increase in total carotenoid content, particularly if the target tissue is deficient in endogenous downstream enzymatic activities. The role of endogenous enzymatic activities in determining the outcome of engineering carotenoid biosynthesis is exemplified by the $\beta$-carotene (pro-vitamin A)-fortified 'Golden Rice' that have been generated through overexpression of a plant $P S Y$ and the bacterial phytoene desaturase gene $\mathrm{CrtI}$ in rice endosperm [215-217]. Endosperm-specific overexpression of $P S Y$ as a single gene resulted in the accumulation of phytoene as the sole carotenoid, suggesting lack of phytoene desaturase activity [200]. Combining PSY with CrtI did not result in the expected accumulation of lycopene, the enzymatic product of CrtI, but led to yellow grains containing $\beta$ - and $\alpha$-carotene, zeaxanthin and lutein [215], due to the presence of endogenous lycopene cyclase and hydroxylase activity in rice endosperm [218]. Similarly, the combined expression of the bacterial $\mathrm{CrtB}$ and $\mathrm{CrtI}$ in Canola seeds led to higher increase in carotenoid content, compared to $\mathrm{CrtB}$ alone [219]. This combination gave also rise to "Golden Wheat" [220], while the generation of "Golden Potato" required the introduction of a bacterial mini-pathway consisting of the three transgenes $\mathrm{CrtB}$, CrtI and CrtY (bacterial LYCB) [221]. For the production of ketocarotenoids in canola, seven bacterial genes, including 5 Pantoea ananatis genes that enable zeaxanthin production from IPP/DMAPP, a Paracoccus IPP/DMAPP isomerase and a Brevundimonas ketolase gene, which led to up to around 1000-fold increase in $\beta$-carotene content and to the accumulation of high amounts of ketocarotenoids, particularly canthaxanthin [222]. More recently, a ketocarotenoid mini-pathway, which consists of four genes including an algal ketolase, was introduced in rice under the control of endosperm-specific promoters. The obtained grains accumulated canthaxanthin and astaxanthin and showed a striking orange-red color [223]. The above 
described examples of introducing complete pathways relied on Agrobacterium mediated transformation of multigene constructs. Alternatively, multi-gene engineering can be achieved using biolistic combinatorial transformation of independent gene constructs. An example for this strategy is the generation of maize lines with different endosperm carotenoid compositions by combining 5 genes [224]. Polycistronic expression different genes coupled with a viral peptidase in a single transcript is a further approach for introducing complete pathways. This strategy ensures coordinated expression of the different enzymes and has been successfully used in carotenoid metabolic engineering [225-227].

Enzyme fusions are a powerful synthetic biology tool that decreases diffusion of intermediates or losing them to a different metabolic route - and ensures simultaneous presence of the fused enzymes. This approach has been recently tested through generation of GGPS11-PSY and CrtZ-CrtW (bacterial $\beta$-carotene hydroxylase-ketolase) fusions. Transgenic Arabidopsis cotyledons and transgenic callus lines expressing the GGPS11-PSY fusion showed higher carotenoid content, compared to single PSY- or GGPS11-overexpressing lines [228]; the chimeric CrtZ-CrtW metabolon increased the efficiency of astaxanthin production E. coli and reduced the amounts of ketocarotenoid intermediates upon transient introduction in Nicotiana benthamiana [85]. A BCH-BKT (fusion of Capsicum $\beta$-carotene hydroxylase and Haematococcus $\beta$-carotene ketolase) has been successfully employed for stepwise metabolic engineering of astaxanthin in rice endosperm [229]. Most of carotenoid-biofortified crops were produced by directing the transgene(s) into the nucleus. However, plastid transformation has been used to modify the carotenoid pattern in tobacco and lettuce [230, 231], and to insert the entire cytosolic mevalonate pathway into tobacco chloroplast genome [232]. The recently reported successful usage of chitosan-complexed single-walled carbon nanotube carriers for 
transgene delivery to chloroplasts is a promising approach that may make the transgenic strategy applicable to wide range of crops and facilitate carotenoid biofortification [233].

The second strategy for carotenoid bio-fortification targets precursor-metabolizing or downstream enzymatic activities, with the aim of reducing the metabolic flux into competing metabolic routes or apocarotenoid formation. This so called "block" strategy utilizes RNA interference-mediated repression- gene silencing- and will benefit from CRISPR gene editing tools to reduce the activity of/disrupt genes that negatively impacts the accumulation of desired carotenoid(s). Gene silencing has been successfully used to increase the carotenoid content in different plant tissues, including petals, tubers and fruits [153, 155, 234-236]. For instance, ZEP, LCYe and $\beta$-Carotene hydroxylase $(\mathrm{CHY}$ or $\mathrm{BCH})$ have been shown to be negative regulators of total carotenoids accumulation in different plant tissues and species [175, 183, 195, 237]. Indeed, silencing of ZEP and $L C Y e$ in potato tubers resulted in significant increase in $\beta$-carotene content $[238,239]$. A further example is the generation of orange fruits biofortified with $\beta$-carotene through silencing of $B C H$ [240]. The combination of the "block strategy", i.e. endosperm-specific silencing of the $B C H$ gene, and the aforementioned "push strategy", i.e. increasing precursor flux by overexpression of $\mathrm{CrtB}$, led to up to 31-fold enhancement of levels of $\beta$-carotene levels in wheat [241]. A similar approach by silencing LCYe and overexpressing PSY, CHY and ketolase was followed to produce astaxanthin in maize endosperm [242].

The third strategy for enhancing carotenoid production is to increase the storage capacity, i.e. the "carotenoid sink", of the target issue, $[44,243]$. One of the most promising "hypothetical" approaches to increase the carotenoid sink is to trigger the differentiation of chromoplasts in the tissue of interest [244]. The discovery of the $O r$ gene has made this approach in several cases feasible and opened up the possibility of generating chromoplasts from other plastid types (see 
above; $[89,90,92,98,243,245])$. Ectopic expression of the Arabidopsis $O r$ in tomato increases also the size of plastids, exerting an additional positive effect on carotenoid accumulation [246]. Size and number of plastids, and, hence, fruit lycopene content, are also increased in the ABA-deficient high pigment 3 mutant and upon fruit-specific, RNAi-mediated suppressing of the photomorphogenesis regulatory gene, DET1 [247-249].

The fourth strategy for carotenoid biofortification aims at increasing the post-harvest stability of carotenoids. Genetic evidence suggests a role of lipoxygenases in degrading wheat carotenoids during storage [118]. Indeed, down-regulation of lipoxygenase activity in Golden Rice increased postharvest carotenoid stability [117]. In potato, it has been shown that the transformation of the cauliflower Or gene also stimulates carotenoid accumulation during cold storage, providing a further evidence for the importance of this gene in determining carotenoid content [244]. Esterification of carotenoids can promote their sequestration and improve their storage stability in wheat and might also reduce carotenoid degradation in citrus fruits [250-253]. Post-harvest carotenoid stability can be also improved by enhancing the antioxidant capacity of the target tissue. For instance, increasing vitamin $\mathrm{E}$ content in transgenic sorghum by co-expressing homogentisate geranylgeranyl transferase (HGGT) with carotenoid biosynthesis genes, resulted in increased $\beta$-carotene accumulation and storage stability [254]. The simultaneous introduction of vitamin $\mathrm{E}$ and $\beta$-carotene biosynthetic genes is a promising strategy for improving the nutritional value of other carotenoid-biofortified cereals.

\section{Are carotenoids from biofortified crops useful?}

Apart from being present in significant concentrations, carotenoids accumulated in biofortified crops need to be released, absorbed and metabolized efficiently to fulfill their function as antioxidants or provitamin A. This complex process is defined by different terms. 
Bioaccessibility refers to the portion of carotenoid that can be released from the food matrix and become accessible for the digestive apparatus and is usually measured in vitro using simulated digestion systems or Caco-2 cells $[255,256]$. Bioavailability defines the portion of diet carotenoids, which is taken up and becomes available for utilization in normal physiological functions, metabolism, and storage and is usually determined by using human volunteers or animal models such as mice, chickens, or Mongolian gerbils. In general, the bioavailability of $\beta$-carotene from plant sources is low (with a maximum of $65 \%$ ), due to the presence of cell walls, fibers and carotene-protein complexes, which hamper digestion and degradation [255], and is increased by cooking and consuming fat-rich food matrix [256]. The terms bioconversion and bioefficacy are more specific to provitamin A carotenoids [256]. Bioconversion (bioactivity) refers to the fraction of the absorbed provitamin A carotenoids that is metabolized into vitamin A (retinol), while bioefficacy defines the efficiency of the absorption of provitamin A carotenoids and their conversion into retinol, and is expressed as retinol equivalents (RE). One RE is defined as the biological activity associated with $1 \mu \mathrm{g}$ of all-trans retinol ([255]; https://www.nrv.gov.au/nutrients/vitamin-a).

Retinol equivalency as well as bioavailability of $\beta$-carotene are affected by several diet-related factors, e.g. fat, fiber, total carotenoid and $\beta$-carotene content, as well as by genetic polymorphisms related to $\beta$-carotene metabolism, vitamin A status and other features of the target population [257]. Retinol equivalency of $\beta$-carotene from plant sources shows large variation, ranging from 3.8:1 to 28:1 [257]. The term Recommended Daily Allowance (RDA) defines the average daily level of intake that is sufficient to meet the nutrient requirements of $\begin{array}{lllll}\text { nearly all } & (97 \%-98 \%) & \text { healthy } & \text { people } & \text { (NIH; }\end{array}$ https://ods.od.nih.gov/Health_Information/Dietary_Reference_Intakes.aspx). None of the five 
major staple crops (wheat, corn, rice, potato, cassava) can provide $25 \%$ of the RDA, which is sufficient to prevent vitamin A deficiency [44]. There are several studies on the bioavailability, bioaccessibility and retinol equivalency of carotenoids from biofortified crops (reviewed in: [44, 256-258]. The bioaccessibility of $\beta$-carotene from biofortified cassava, melon, sorghum and potato is comparable with that from the corresponding original varieties [44]. Studies on the bioavailability of $\beta$-carotene from biofortified crops showed RE ratios of 3:1 (transgenic maize), 3.5-6.5:1 (sweet potato), 3.7:1 (cassava), 3.8-6.5:1 (non-transgenic, biofortified maize), 4.2:1 (non-transgenic biofortified cassava) and 2.3:1 (Golden Rice) which are significantly lower than those of vegetables [257]. Several in vivo studies demonstrated that consuming provitamin A carotenoids (e.g. $\beta$-carotene) from biofortified crops help increases vitamin A intake and status. For example, consumption of biofortified orange sweet potato improved total-body vitamin A stores across different age groups [255, 259, 260]. Similarly, intake of biofortified orange maize resulted in a significant improvement in vitamin A status, indicated by an increase in pupillary responsiveness, of marginally vitamin A deficient children [255, 261]. Finally, Golden Rice has the potential to fulfill up to $89-113 \%$ and $57-99 \%$ of the estimated average requirement for vitamin A for preschool children in Bangladesh and the Philippines, respectively [258]. Fortunately, Bangladesh, a country where vitamin A deficiency affects about $21 \%$ of children, is expected to approve Golden Rice for planting soon [223].

Golden Rice has been already documented as safe for human consumption in several countries, including United States, Australia, Canada and New Zealand [224]. Very recently, Golden Rice has been also approved "as safe as conventional rice" by the Department of Agriculture in the Philippines, which paves the way for its employment in combating VAD (https://www.newscientist.com/article/2228793-gm-golden-rice-gets-landmark-safety-approval-i 
n-the-philippines/).

Biofortified crops have been also shown to an efficient source of carotenoids for animals. For example, feeding poultry with carotenoid biofortified maize enhanced the accumulation of carotenoids in muscles, skin and egg yolk, and increased liver vitamin A content under lab and farm conditions [262]. In addition, carotenoids from biofortified maize has been shown to protect broilers against coccidiosis without the need for artificial carotenoid additives [263]. Astaxanthin is the most expensive fish food ingredient added to obtain a desirable pink flesh color of salmon and trout. Biological sources of this ketocarotenoid are not sufficient to meet the global astaxanthin demand [262]. Recently, astaxanthin-biofortified transgenic maize and tomato fruit have been shown to be more efficient in conferring the desired color to egg yolk and salmon flesh, respectively, compared to synthetic astaxanthin additives [41, 263]

\section{Future Perspectives}

Conventional breeding is a classical approach that has been used to increase carotenoid content in crops, such as maize and carrot (Fig. 3). However, classical breeding is a relatively slow and laborious process and can be deployed only in species in which natural variation in carotenoid content is high. This is true for some staple crops, such as maize, sweet potato and cassava, while in the case of rice, wheat, and potato, the use of different approaches to increase genetic variation, such as radiation or chemical mutagenesis, gene editing, cis- and/or transgenesis, is essential [44]. In the last decades, genetic engineering of carotenoid biosynthesis has relied mainly on transgenesis, and has generated several carotenoid biofortified crops that hold promise for combating vitamin A deficiency and increasing the nutritional value of plant-derived diets for a better health (Table 1 and Fig. 3). However, transgenic crops have to achieve a broad public acceptance in some areas of the world, and to fulfill stringent legal and regulatory requirements, 
which make their deployment costly and time-consuming. Gene editing tools, such as the CRISPR/Cas system, allow the production of biofortified, non-transgenic crops that do not contain foreign genes [264-269]. Such an approach may find a better public acceptance and accelerate the regulatory approval process, thus bringing biotech crops faster to market [205, 268]. There are already examples for employing the CRISPR/Cas9 technology to alter carotenoid content in flower, callus and fruit $[159,196,270]$. Obvious targets for gene editing are the $B C H$, LCYe and ZEP genes that have a negative impact on $\beta$-carotene content. In addition, the development of CRISPR mediated targeted 'base editing' tools [189], allows precise manipulation of structural or regulatory genes, such as the introduction of the 'Golden SNP' into the $O r$ gene [196]. Gene editing may also accelerate the introduction of entire metabolic pathways and stacking of multiple genes [271], which is required to produce carotenoids in tissues such as rice endosperm. The combination of transgenic approaches with conventional breeding (crossing or introgression) is a further direction for integrated carotenoid biotechnology, which has been recently used in carotenoid biofortification in important crops such as tomato and rice [229, 272]. In countries where gene editing is regulated like transgenesis, more imprecise and laborious techniques like TILLING may find application.

Areas requiring further research are genetic variation of carotenoid content in crop plants, the mechanisms regulating the pathway, including those triggered by end products and intermediates, and the mechanisms governing carotenoid stability and sequestration. Advancement of knowledge in these key areas will not only accelerate modern breeding, but also provide new engineering targets for carotenoid biofortification in crop plants. The combination of genomics-assisted breeding and knowledge-based transgenic and/or gene editing approaches holds promise for the successful biofortification of further crop plants, thus reducing the global 
burden of vitamin A deficiency.

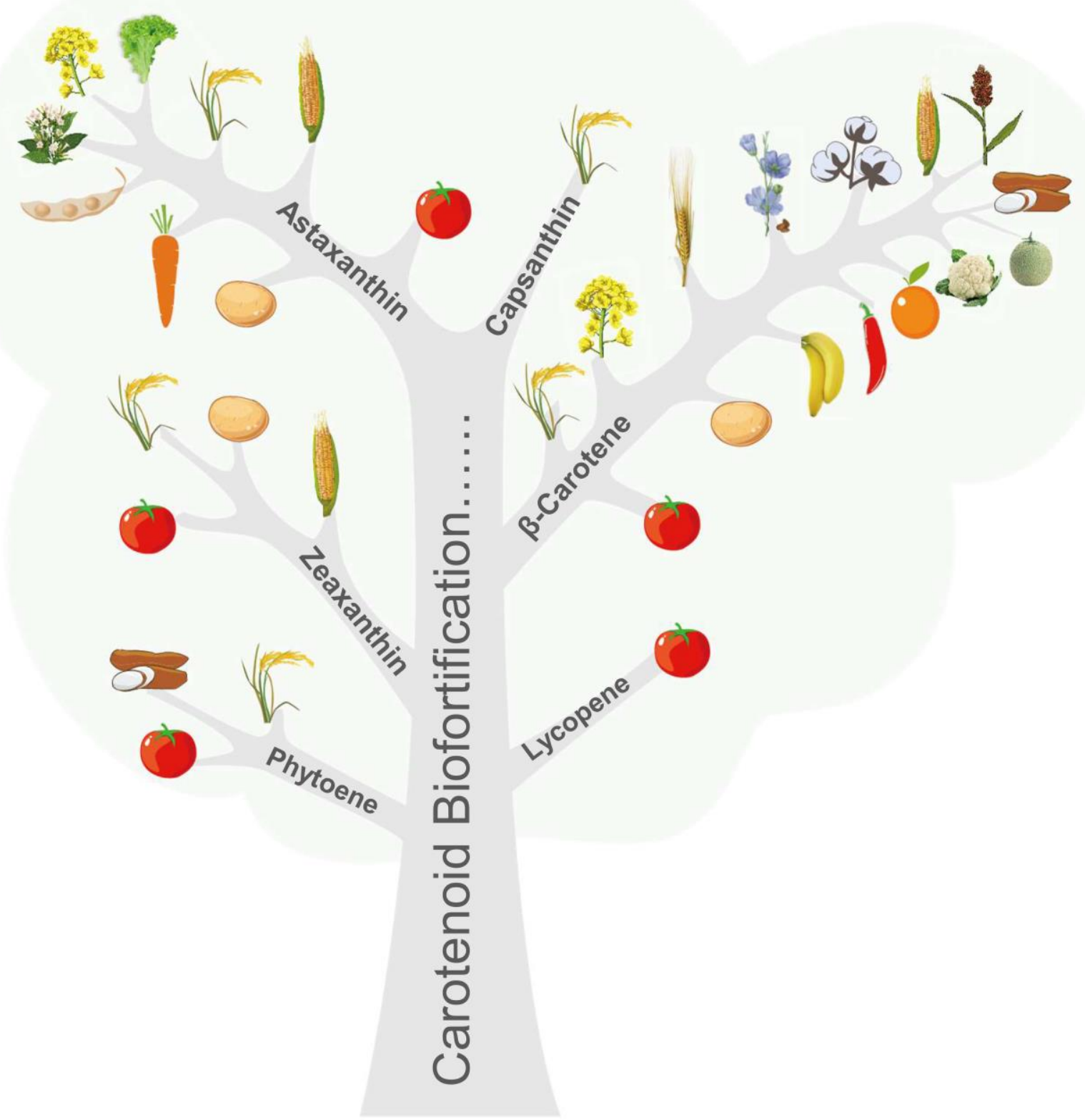

Figure 3. Summary of representative Carotenoids biofortified crop plants developed by transgenic and breeding approaches. Phytoene biofortified crop plants: Tomato, rice and cassava; Lycopene biofortified crop: Tomato; $\beta$-carotene biofortified crops: Tomato, rice, canola (Brassica napus), potato, wheat, banana, flaxseed (Linum usitatissimum), pepper, orange, cotton, 
maize, sorghum, cassava, cauliflower and melon. Zeaxanthin biofortified crops; Tomato, maize, potato and rice. Capsanthin biofortified crop: Rice; Astaxanthin biofortified crops; Potato, carrot, maize, rice, soybean, tobacco, canola and lettuce. The detail of metabolic engineering of plant carotenoids is shown in Table 1. 
Table 1. Metabolic engineering for carotenoids biofortification in crop plants.

\begin{tabular}{|c|c|c|c|}
\hline $\begin{array}{l}\text { Plant } \\
\text { species }\end{array}$ & Strategy & Phenotypic changes in carotenoids & Reference(s) \\
\hline \multirow{20}{*}{ Tomato } & Nuclear transformation & & \\
\hline & $D X S$ overexpression & Enhanced fruit carotenoids & [214] \\
\hline & Or Overexpression & Increase of total carotenoids & {$[246]$} \\
\hline & FIBRILLIN overexpression & $\begin{array}{l}\text { Enhanced carotenoids, carotenoid-derived } \\
\text { volatiles }\end{array}$ & [273] \\
\hline & PSY1 overexpression & Enhanced phytoene, $\beta$-carotene & [199] \\
\hline & PDS overexpression & Enhancement of lycopene, $\beta$-carotene & [201] \\
\hline & $B K T, C H Y$ overexpression & $\begin{array}{l}\text { Astaxanthin accumulation in leaves, } \\
\text { esterified astaxanthin accumulation in fruits }\end{array}$ & {$[274]$} \\
\hline & $C R Y 2$ overexpression & Enhanced carotenoids & {$[275]$} \\
\hline & $\begin{array}{l}\text { DET1, DDB1, COPl-like } \\
\text { silencing }\end{array}$ & Enhanced carotenoids & {$[247,248,276]$} \\
\hline & $C r t B$ overexpression & Enhanced lycopene in fruit & [226] \\
\hline & $C Y C b, L C Y b$ silencing & Enhanced lycopene in fruit & {$[71,237]$} \\
\hline & CrtI overexpression & $\beta$-carotene accumulation in fruit & {$[277]$} \\
\hline & $\begin{array}{l}L C Y b \quad \text { and } \\
\text { overexpression }\end{array}$ & $\beta$-carotene, zeaxanthin accumulation & {$[237,278,279]$} \\
\hline & $\begin{array}{l}C r t B, \quad C r t E \text { and } C r t I \\
\text { overexpression }\end{array}$ & $\begin{array}{l}\text { Accumulation of different carotenoids in } \\
\text { different sub-chromoplast compartments }\end{array}$ & [280] \\
\hline & $\begin{array}{l}\text { RNAi of } S G R 1 \text {, CRISPR } \\
\text { mediated gene knock-out of } \\
\text { SGRl }\end{array}$ & Enhancement of lycopene, $\beta$-carotene & {$[270,281]$} \\
\hline & $\begin{array}{l}C r t Z, \quad W \\
\text { overexpression }\end{array}$ & $\begin{array}{l}\text { Ketocarotenoid accumulation in fruit and } \\
\text { leaves }\end{array}$ & {$[41,226]$} \\
\hline & $C r t Z$ and $W$ overexpression & $\begin{array}{l}\text { Overproduction of lycopene, accumulation } \\
\text { of astaxanthin }\end{array}$ & [282] \\
\hline & $B Z R I-1 D$ overexpression & Enhancement of carotenoid accumulation & [283] \\
\hline & MADS6 overexpression & Enhancement of carotenoid accumulation & {$[174]$} \\
\hline & $B B X 20$ overexpression & Enhancement of carotenoid accumulation & {$[172]$} \\
\hline \multirow[t]{6}{*}{ Rice } & $P S Y, C r t I$ overexpression & $\begin{array}{l}\beta \text {-carotene. zeaxanthin accumulation in } \\
\text { endosperm }\end{array}$ & $\begin{array}{l}{[188,200,215,} \\
227]\end{array}$ \\
\hline & $\begin{array}{l}\text { Combinatorial } \\
\text { overexpression of Psyl, } \\
D X S, C r t I, O R, B K T\end{array}$ & $\begin{array}{l}\text { Accumulation of different carotenoids in } \\
\text { endosperm }\end{array}$ & [284] \\
\hline & Combinatorial & Ketocarotenoid accumulation in endosperm & [285] \\
\hline & $\begin{array}{l}\text { Overexpression of Psyl, } \\
C r t I, B K T\end{array}$ & & \\
\hline & $\begin{array}{l}P S Y 1, C r t I, B K T \text { and } B C H \\
\text { overexpression }\end{array}$ & Ketocarotenoid accumulation in endosperm & [223] \\
\hline & $\begin{array}{l}\text { PSY-CrtI polyprotein and } \\
\text { BCH-BKT polyprotein } \\
\text { overexpression }\end{array}$ & $\begin{array}{l}\text { Accumulation of zeaxanthin, astaxanthin } \\
\text { and capsanthin in endosperm }\end{array}$ & [229] \\
\hline \multirow[t]{8}{*}{ Potato } & $\mathrm{CrtO}$ overexpression & $\begin{array}{l}\text { Ketocarotenoid accumulation in leaves, } \\
\text { tubers }\end{array}$ & {$[286,287]$} \\
\hline & $\begin{array}{l}\text { CrtW, } \quad C r t Z \quad O r \\
\text { overexpression }\end{array}$ & Astaxanthin accumulation in tubers & [288] \\
\hline & $C r t B, I, Y$ overexpression & $\alpha$-, $\beta$-carotene accumulation in tubers & {$[221,289,290]$} \\
\hline & $D X S$ overexpression & Enhanced total carotenoids & [213] \\
\hline & $Z E P$ silencing & Zeaxanthin accumulation in tubers & {$[238]$} \\
\hline & LCYe silencing & $\begin{array}{l}\text { Enhanced } \beta \text {-carotene, total carotenoids in } \\
\text { tubers }\end{array}$ & {$[239]$} \\
\hline & $\mathrm{CHY}$ silencing & Enhanced $\beta$-carotene in tubers & {$[291,292]$} \\
\hline & Or overexpression & $\begin{array}{l}\beta \text {-carotene, total carotenoid accumulation in } \\
\text { tubers }\end{array}$ & {$[90,293]$} \\
\hline
\end{tabular}


RNAi of $C C D 4$

Combinatorial overexpression CrtI, Chy, LCYb, CrtW

Combined overexpression of Psyl, CrtI, Dhar, FolE

Psyl, CrtZ, Bkt overexpression, LCYe silencing

Wheat

CrtB, CrtI overexpression

CrtB overexpression, $\mathrm{CHY}$ silencing

Banana

$P S Y$ overexpression

Sorghum

Cotton

Brassica napus

Carrot

Cassava

Lilium

Lotus

japonicus

Orange

Sweet potato

Nicotiana

plant

Psyl, CrtI, HGGT overexpression

Psyl-CrtI polyprotein overexpression

$\mathrm{CrtB}, \quad \mathrm{CrtW}$ overexpression

Psy overexpression in seed

$C r t B, I, Y$ overexpression

IDI, CrtE, CrtB, CrtI, CrtY $C r t W, C r t Z$ overexpression

$\mathrm{CrtO}$ overexpression

$\mathrm{CrtB}$ overexpression in root

IDI, CrtE, CrtB, CrtI, CrtY $C r t W, C r t Z$ overexpression

$C r t W$ overexpression

CHY silencing

Or overexpression

CrtZ, W polyprotein overexpression

$\mathrm{Cr} Z \mathrm{Z}$ overexpression

$\mathrm{CrtO}$ overexpression

$C r t Z$ and $W$ overexpression

Plastid transformation

Tomato fruit $L C Y b, C r t Y$ overexpression
Increased carotenoid content in tubers and [153]

flowers

Increase of total carotenoids

Increase of $\beta$-carotene content

Accumulation of astaxanthin, [242]

ketozeaxanthin

Increase of carotenoid and $\beta$-carotene in endosperm

Enhanced $\beta$-carotene accumulation in endosperm

Enhanced $\beta$-carotene accumulation in fruit

$\beta$-carotene, vitamin $\mathrm{E}$ accumulation in endosperm

$[254,296]$

$\beta$-carotene accumulation in seed

$\alpha-, \beta$-carotene accumulation in seed

[222]

$\beta$-carotene, ketocarotenoid accumulation in seed

Ketocarotenoid accumulation in leaves and roots

[186] Accumulation of
$\beta$-carotene in root.

Ketocarotenoid accumulation in leaves.

[300]

Ketocarotenoid accumulation in flower

[301]

$\beta$-carotene accumulation in fruit pulp

Increase in total carotenoids in root

Ketocarotenoid accumulation in leaves and nectary (flower)

Enhanced zeaxanthin biosynthesis under high light, enhanced UV tolerance

Ketocarotenoid accumulation in leaves, [304-306] nectary, petals

$\beta$-carotene accumulation, increase of total

$[308,309]$ carotenoid 


\begin{tabular}{|c|c|c|c|}
\hline $\begin{array}{l}\text { Lettuce } \\
\text { leaves }\end{array}$ & $\begin{array}{l}C r t Z, \quad \mathrm{Crt} W, \\
\text { overexpression }\end{array}$ & Astaxanthin ester accumulation & [231] \\
\hline $\begin{array}{l}\text { Tobacco } \\
\text { leaves }\end{array}$ & $C r t Z, C r t W$ overexpression & $\begin{array}{l}\text { Astaxanthin, } \\
\text { accumulation }\end{array}$ & {$[230,310]$} \\
\hline
\end{tabular}

\section{Declaration of Competing Interest}

The Authors declare no conflict of interest related to this work.

\section{Acknowledgment}

We thank Dr. Jianing Mi for valuable discussions. This work was supported by base line funding given to Salim Al-Babili from King Abdullah University for Science and Technology and by grants from the European Commission (projects G2P-SOL and Newcotiana) to Giovanni Giuliano. 


\section{Reference}

[1] M. Rodriguez-Concepcion, J. Avalos, M.L. Bonet, A. Boronat, L. Gomez-Gomez, D. Hornero-Mendez, et al., A global perspective on carotenoids: Metabolism, biotechnology, and benefits for nutrition and health, Prog. Lipid. Res., 70 (2018) 62-93.

[2] A.R. Moise, S. Al-Babili, E.T. Wurtzel, Mechanistic aspects of carotenoid biosynthesis, Chem. Rev., 114 (2013) 164-193.

[3] J. Hirschberg, Carotenoid biosynthesis in flowering plants, Curr. Opin. Biotechnol., 4 (2001) 210-218.

[4] P.D. Fraser, P.M. Bramley, The biosynthesis and nutritional uses of carotenoids, Prog. Lipid. Res., 43 (2004) 228-265.

[5] N. Nisar, L. Li, S. Lu, N.C. Khin, B.J. Pogson, Carotenoid metabolism in plants, Mol. Plant., 8 (2015) 68-82.

[6] H. Yuan, J. Zhang, D. Nageswaran, L. Li, Carotenoid metabolism and regulation in horticultural crops, Hortic. Res., 2 (2015) 15036.

[7] M.H. Walter, D. Strack, Carotenoids and their cleavage products: biosynthesis and functions, Nat. Prod. Rep., 28 (2011) 663-692.

[8] P.A. Svensson, B. Wong, Carotenoid-based signals in behavioural ecology: a review, Behaviour, 148 (2011) 131-189.

[9] T. Maoka, Carotenoids in marine animals, Marine drugs, 9 (2011) 278-293.

[10] H. Hashimoto, C. Uragami, R.J. Cogdell, Carotenoids and photosynthesis, Subcell Biochem, 79 (2016), pp. 111-139.

[11] S.H. Schwartz, B.C. Tan, D.A. Gage, J.A. Zeevaart, D.R. McCarty, Specific oxidative cleavage of carotenoids by VP14 of maize, Science, 276 (1997) 1872-1874.

[12] S. Al-Babili, H.J. Bouwmeester, Strigolactones, a novel carotenoid-derived plant hormone, Annu. Rev. Plant Biol., 66 (2015) 161-186.

[13] K.-P. Jia, L. Baz, S. Al-Babili, From carotenoids to strigolactones, J. Exp. Biol., 69 (2017) 2189-2204.

[14] A. Felemban, J. Braguy, M.D. Zurbriggen, S. Al-Babili, Apocarotenoids Involved in Plant Development and Stress Response, Front. Plant Sci., 10 (2019) 1168. 
[15] V. Fiorilli, J.Y. Wang, P. Bonfante, L. Lanfranco, S. Al-Babili, Apocarotenoids: old and new mediators of the arbuscular mycorrhizal symbiosis, Front. Plant Sci., 10 (2019) 1186.

[16] F. Ramel, S. Birtic, C. Ginies, L. Soubigou-Taconnat, C. Triantaphylides, M. Havaux, Carotenoid oxidation products are stress signals that mediate gene responses to singlet oxygen in plants, Proc. Natl. Acad. Sci. U. S. A., 109 (2012) 5535-5540.

[17] A.J. Dickinson, K. Lehner, J. Mi, K.-P. Jia, M. Mijar, J. Dinneny, et al., $\beta$-Cyclocitral is a conserved root growth regulator, Proc. Natl. Acad. Sci. U. S. A., 116 (2019) 10563-10567.

[18] J.Y. Wang, I. Haider, M. Jamil, V. Fiorilli, Y. Saito, J. Mi, et al., The apocarotenoid metabolite zaxinone regulates growth and strigolactone biosynthesis in rice, Nat. Commun., 10 (2019) 810.

[19] K.-P. Jia, A.J. Dickinson, J. Mi, G. Cui, T.T. Xiao, N.M. Kharbatia, et al., Anchorene is a carotenoid-derived regulatory metabolite required for anchor root formation in Arabidopsis, Sci. Adv., 5 (2019) eaaw6787.

[20] A.R. Moise, J. von Lintig, K. Palczewski, Related enzymes solve evolutionarily recurrent problems in the metabolism of carotenoids, Trends. Plant. Sci., 10 (2005) 178-186.

[21] G. Giuliano, S. Al-Babili, J. Von Lintig, Carotenoid oxygenases: cleave it or leave it, Trends. Plant. Sci., 8 (2003) 145-149.

[22] H.R. Medina, E. Cerdá-Olmedo, S. Al-Babili, Cleavage oxygenases for the biosynthesis of trisporoids and other apocarotenoids in Phycomyces, Mol. Microbiol., 82 (2011) 199-208.

[23] X. Sui, P.D. Kiser, J. von Lintig, K. Palczewski, Structural basis of carotenoid cleavage: from bacteria to mammals, Archives of biochemistry and biophysics, 539 (2013) 203-213.

[24] J.N. Siedow, Plant lipoxygenase: structure and function, Annu. Rev. Plant Biol., 42 (1991) 145-188.

[25] S. Hayward, Partial characterization of lentil seed lipoxygenases and their impact in wheat (Triticum aestivum L.) bread making, in, Stellenbosch: Stellenbosch University, 2017.

[26] X. Hou, J. Rivers, P. León, R.P. McQuinn, B.J. Pogson, Synthesis and function of apocarotenoid signals in plants, Trends. Plant. Sci., 21 (2016) 792-803.

[27] J. Von Lintig, Colors with functions: elucidating the biochemical and molecular basis of carotenoid metabolism, Annu. Rev. Nutr., 30 (2010) 35-56.

[28] E.H. Harrison, Mechanisms of digestion and absorption of dietary vitamin A, Annu. Rev. Nutr., 25 (2005) 87-103. 
[29] S. Voutilainen, T. Nurmi, J. Mursu, T.H. Rissanen, Carotenoids and cardiovascular health, Am. J. Clin. Nutr., 83 (2006) 1265-1271.

[30] M. Shareck, M.-C. Rousseau, A. Koushik, J. Siemiatycki, M.-E. Parent, Inverse association between dietary intake of selected carotenoids and vitamin $\mathrm{C}$ and risk of lung cancer, Front. Oncol., 7 (2017) 23.

[31] E.J. Johnson, Role of lutein and zeaxanthin in visual and cognitive function throughout the lifespan, Nutr. Rev., 72 (2014) 605-612.

[32] L. Ma, S.-F. Yan, Y.-M. Huang, X.-R. Lu, F. Qian, H.-L. Pang, et al., Effect of lutein and zeaxanthin on macular pigment and visual function in patients with early age-related macular degeneration, Ophthalmology, 119 (2012) 2290-2297.

[33] J.R. Mein, F. Lian, X.-D. Wang, Biological activity of lycopene metabolites: implications for cancer prevention, Nutr. Rev., 66 (2008) 667-683.

[34] J. Erdman, J. Smith, M. Kuchan, E. Mohn, E. Johnson, S. Rubakhin, et al., Lutein and brain function, Foods, 4 (2015) 547-564.

[35] E.J. Johnson, R. Vishwanathan, M.A. Johnson, D.B. Hausman, A. Davey, T.M. Scott, et al., Relationship between serum and brain carotenoids,-tocopherol, and retinol concentrations and cognitive performance in the oldest old from the Georgia Centenarian Study, J. Aging Res., 2013 (2013).

[36] E.R. Bovier, L.M. Renzi, B.R. Hammond, A double-blind, placebo-controlled study on the effects of lutein and zeaxanthin on neural processing speed and efficiency, PloS one, 9 (2014) e108178.

[37] A.J. Meléndez-Martínez, P. Mapelli-Brahm, C.M. Stinco, The colourless carotenoids phytoene and phytofluene: From dietary sources to their usefulness for the functional foods and nutricosmetics industries, J. Food Compos. Anal., 67 (2018) 91-103.

[38] B. Fuller, D. Smith, A. Howerton, D. Kern, Anti-inflammatory effects of CoQ10 and colorless carotenoids, J. Cosmet. Dermatol., 5 (2006) 30-38.

[39] A.J. Meléndez-Martínez, P. Mapelli-Brahm, A. Benítez-González, C.M. Stinco, A comprehensive review on the colorless carotenoids phytoene and phytofluene, Arch. Biochem. Biophys., 572 (2015) 188-200.

[40] D. Steven, Studies on animal carotenoids: I. Carotenoids of the brown trout (Salmo trutta linn.), J. Exp. Biol., 25 (1948) 369-387.

[41] M. Nogueira, E.M.A. Enfissi, M.E. Martinez Valenzuela, G.N. Menard, R.L. Driller, P.J. Eastmond, et al., Engineering of tomato for the sustainable production of ketocarotenoids and its evaluation in aquaculture feed, Proc. Natl. Acad. Sci. U. S. A., 114 (2017) 10876-10881. 
[42] N.I. Krinsky, E.J. Johnson, Carotenoid actions and their relation to health and disease, Mol. Aspects. Med., 26 (2005) 459-516.

[43] K.P. West, I. Darnton-Hill, Vitamin A deficiency, in: Nutrition and health in developing countries, Springer, 2008, pp. 377-433.

[44] G. Giuliano, Provitamin A biofortification of crop plants: a gold rush with many miners, Curr. Opin. Biotechnol., 44 (2017) 169-180.

[45] E. Vranová, D. Coman, W. Gruissem, Network analysis of the MVA and MEP pathways for isoprenoid synthesis, Annu. Rev. Plant Biol., 64 (2013) 665-700.

[46] P. Pulido, C. Perello, M. Rodriguez-Concepcion, New insights into plant isoprenoid metabolism, Mol. Plant., 5 (2012) 964-967.

[47] M. Rodríguez-Concepción, A. Boronat, Breaking new ground in the regulation of the early steps of plant isoprenoid biosynthesis, Curr. Opin. Biotechnol., 25 (2015) 17-22.

[48] M. Rodriguez-Concepción, A. Boronat, Elucidation of the methylerythritol phosphate pathway for isoprenoid biosynthesis in bacteria and plastids. A metabolic milestone achieved through genomics, Plant Physiol, 130 (2002) 1079-1089.

[49] O. Laule, A. Fürholz, H.-S. Chang, T. Zhu, X. Wang, P.B. Heifetz, et al., Crosstalk between cytosolic and plastidial pathways of isoprenoid biosynthesis in Arabidopsis thaliana, Proc. Natl. Acad. Sci. U. S. A., 100 (2003) 6866-6871.

[50] A. Hemmerlin, J.-F. Hoeffler, O. Meyer, D. Tritsch, I.A. Kagan, C. Grosdemange-Billiard, et al., Cross-talk between the cytosolic mevalonate and the plastidial methylerythritol phosphate pathways in tobacco bright yellow-2 cells, J. Biol. Chem., 278 (2003) 26666-26676.

[51] N. Dudareva, S. Andersson, I. Orlova, N. Gatto, M. Reichelt, D. Rhodes, et al., The nonmevalonate pathway supports both monoterpene and sesquiterpene formation in snapdragon flowers, Proc. Natl. Acad. Sci. U. S. A., 102 (2005) 933-938.

[52] H. Paetzold, S. Garms, S. Bartram, J. Wieczorek, E.-M. Urós-Gracia, M. Rodríguez-Concepción, et al., The isogene 1-deoxy-D-xylulose 5-phosphate synthase 2 controls isoprenoid profiles, precursor pathway allocation, and density of tomato trichomes, Mol. Plant., 3 (2010) 904-916.

[53] L.P. Wright, J.M. Rohwer, A. Ghirardo, A. Hammerbacher, M. Ortiz-Alcaide, B. Raguschke, et al., Deoxyxylulose 5-phosphate synthase controls flux through the methylerythritol 4-phosphate pathway in Arabidopsis, Plant Physiol, 165 (2014) 1488-1504.

[54] A. Banerjee, T. Sharkey, Methylerythritol 4-phosphate (MEP) pathway metabolic regulation, Nat. Prod. Rep., 31 (2014) 1043-1055. 
[55] A. Hemmerlin, Post-translational events and modifications regulating plant enzymes involved in isoprenoid precursor biosynthesis, Plant Sci., 203 (2013) 41-54.

[56] P. Pulido, G. Toledo-Ortiz, M.A. Phillips, L.P. Wright, M. Rodríguez-Concepción, Arabidopsis J-protein $\mathrm{J} 20$ delivers the first enzyme of the plastidial isoprenoid pathway to protein quality control, Plant Cell, 25 (2013) 4183-4194.

[57] P. Pulido, E. Llamas, B. Llorente, S. Ventura, L.P. Wright, M. Rodríguez-Concepción, Specific Hsp100 chaperones determine the fate of the first enzyme of the plastidial isoprenoid pathway for either refolding or degradation by the stromal Clp protease in Arabidopsis, PLoS Genet., 12 (2016) e1005824.

[58] Ú. Flores-Pérez, S. Sauret-Güeto, E. Gas, P. Jarvis, M. Rodríguez-Concepción, A mutant impaired in the production of plastome-encoded proteins uncovers a mechanism for the homeostasis of isoprenoid biosynthetic enzymes in Arabidopsis plastids, Plant Cell, 20 (2008) 1303-1315.

[59] B. Zybailov, G. Friso, J. Kim, A. Rudella, V.R. Rodriguez, Y. Asakura, et al., Large scale comparative proteomics of a chloroplast Clp protease mutant reveals folding stress, altered protein homeostasis, and feedback regulation of metabolism, Mol Cell Proteomics., 8 (2009) $1789-1810$.

[60] Y. Balmer, A. Koller, G. del Val, W. Manieri, P. Schürmann, B.B. Buchanan, Proteomics gives insight into the regulatory function of chloroplast thioredoxins, Proc. Natl. Acad. Sci. U. S. A., 100 (2003) 370-375.

[61] A. Banerjee, Y. Wu, R. Banerjee, Y. Li, H. Yan, T.D. Sharkey, Feedback inhibition of deoxy-D-xylulose-5-phosphate synthase regulates the methylerythritol 4-phosphate pathway, J. Biol. Chem., 288 (2013) 16926-16936.

[62] A. Ghirardo, L.P. Wright, Z. Bi, M. Rosenkranz, P. Pulido, M. Rodríguez-Concepción, et al., Metabolic flux analysis of plastidic isoprenoid biosynthesis in poplar leaves emitting and nonemitting isoprene, Plant Physiol, 165 (2014) 37-51.

[63] P.D. Fraser, S. Romer, C.A. Shipton, P.B. Mills, J.W. Kiano, N. Misawa, et al., Evaluation of transgenic tomato plants expressing an additional phytoene synthase in a fruit-specific manner, Proc. Natl. Acad. Sci. U. S. A., 99 (2002) 1092-1097.

[64] M.Á. Ruiz-Sola, M. Rodríguez-Concepción, Carotenoid biosynthesis in Arabidopsis: a colorful pathway, The Arabidopsis book/American Society of Plant Biologists, 10 (2012).

[65] G. Giuliano, L. Giliberto, C. Rosati, Carotenoid isomerase: a tale of light and isomers, Trends. Plant. Sci., 7 (2002) 427-429.

[66] T. Isaacson, I. Ohad, P. Beyer, J. Hirschberg, Analysis in vitro of the enzyme CRTISO establishes a poly-cis-carotenoid biosynthesis pathway in plants, Plant Physiol, 136 (2004) 
$4246-4255$.

[67] J. Breitenbach, G. Sandmann, $\zeta$-Carotene cis isomers as products and substrates in the plant poly-cis carotenoid biosynthetic pathway to lycopene, Planta, 220 (2005) 785-793.

[68] E.T. Wurtzel, Changing form and function through carotenoids and synthetic biology, Plant Physiol, (2019) pp. 01122.02018.

[69] P. Schaub, Q. Yu, S. Gemmecker, P. Poussin-Courmontagne, J. Mailliot, A.G. McEwen, et al., On the structure and function of the phytoene desaturase CRTI from Pantoea ananatis, a membrane-peripheral and FAD-dependent oxidase/isomerase, PLoS One, 7 (2012) e39550.

[70] D.E. Kachanovsky, S. Filler, T. Isaacson, J. Hirschberg, Epistasis in tomato color mutations involves regulation of phytoene synthase 1 expression by cis-carotenoids, Proc. Natl. Acad. Sci. U. S. A., 109 (2012) 19021-19026.

[71] G. Ronen, L. Carmel-Goren, D. Zamir, J. Hirschberg, An alternative pathway to $\beta$-carotene formation in plant chromoplasts discovered by map-based cloning of Beta and old-gold color mutations in tomato, Proc. Natl. Acad. Sci. U. S. A., 97 (2000) 11102-11107.

[72] F.X. Cunningham, E. Gantt, One ring or two? Determination of ring number in carotenoids by lycopene $\varepsilon$-cyclases, Proc. Natl. Acad. Sci. U. S. A., 98 (2001) 2905-2910.

[73] Z. Sun, E. Gantt, F.X. Cunningham, Cloning and functional analysis of the $\beta$-carotene hydroxylase of Arabidopsis thaliana, J. Biol. Chem., 271 (1996) 24349-24352.

[74] L. Tian, D. DellaPenna, Characterization of a second carotenoid $\beta$-hydroxylase gene from Arabidopsis and its relationship to the LUT1 locus, Plant Mol. Biol., 47 (2001) 379-388.

[75] A. Fiore, L. Dall'Osto, P.D. Fraser, R. Bassi, G. Giuliano, Elucidation of the $\beta$-carotene hydroxylation pathway in Arabidopsis thaliana, FEBS Lett., 580 (2006) 4718-4722.

[76] L. Tian, M. Magallanes-Lundback, V. Musetti, D. DellaPenna, Functional analysis of $\beta$-and E-ring carotenoid hydroxylases in Arabidopsis, Plant Cell, 15 (2003) 1320-1332.

[77] B. Pogson, K.A. McDonald, M. Truong, G. Britton, D. DellaPenna, Arabidopsis carotenoid mutants demonstrate that lutein is not essential for photosynthesis in higher plants, Plant Cell, 8 (1996) 1627-1639.

[78] A. Fiore, L. Dall'Osto, S. Cazzaniga, G. Diretto, G. Giuliano, R. Bassi, A quadruple mutant of Arabidopsis reveals a $\beta$-carotene hydroxylation activity for LUT1/CYP97C1 and a regulatory role of xanthophylls on determination of the PSI/PSII ratio, BMC plant biology, 12 (2012) 50.

[79] B. Demmig-Adams, W.W. Adams, Xanthophyll cycle and light stress in nature: uniform response to excess direct sunlight among higher plant species, Planta, 198 (1996) 460-470. 
[80] H.M. North, A.D. Almeida, J.P. Boutin, A. Frey, A. To, L. Botran, et al., The Arabidopsis ABA-deficient mutant aba4 demonstrates that the major route for stress-induced ABA accumulation is via neoxanthin isomers, Plant J, 50 (2007) 810-824.

[81] H. Neuman, N. Galpaz, F.X. Cunningham Jr, D. Zamir, J. Hirschberg, The tomato mutation $n x d l$ reveals a gene necessary for neoxanthin biosynthesis and demonstrates that violaxanthin is a sufficient precursor for abscisic acid biosynthesis, Plant J, 78 (2014) 80-93.

[82] F. Bouvier, P. Hugueney, A. d'Harlingue, M. Kuntz, B. Camara, Xanthophyll biosynthesis in chromoplasts: isolation and molecular cloning of an enzyme catalyzing the conversion of 5, 6epoxycarotenoid into ketocarotenoid, Plant J, 6 (1994) 45-54.

[83] F.X. Cunningham, E. Gantt, Elucidation of the pathway to astaxanthin in the flowers of Adonis aestivalis, Plant Cell, 23 (2011) 3055-3069.

[84] M. Shah, R. Mahfuzur, Y. Liang, J.J. Cheng, M. Daroch, Astaxanthin-producing green microalga Haematococcus pluvialis: from single cell to high value commercial products, Front. Plant Sci., 7 (2016) 531.

[85] M. Nogueira, E.M. Enfissi, R. Welsch, P. Beyer, M.D. Zurbriggen, P.D. Fraser, Construction of a fusion enzyme for astaxanthin formation and its characterisation in microbial and plant hosts: A new tool for engineering ketocarotenoids, Metab. Eng., 52 (2019) 243-252.

[86] C.A. Howitt, B.J. Pogson, Carotenoid accumulation and function in seeds and non-green tissues, Plant Cell. Environ., 29 (2006) 435-445.

[87] G. Britton, Structure and properties of carotenoids in relation to function, FASEB J., 9 (1995) 1551-1558.

[88] D. Maass, J. Arango, F. Wüst, P. Beyer, R. Welsch, Carotenoid crystal formation in Arabidopsis and carrot roots caused by increased phytoene synthase protein levels, PloS one, 4 (2009) e6373.

[89] T. Sun, H. Yuan, H. Cao, M. Yazdani, Y. Tadmor, L. Li, Carotenoid metabolism in plants: the role of plastids, Mol. Plant., 11 (2018) 58-74.

[90] S. Lu, J. Van Eck, X. Zhou, A.B. Lopez, D.M. O'Halloran, K.M. Cosman, et al., The cauliflower Or gene encodes a DnaJ cysteine-rich domain-containing protein that mediates high levels of beta-carotene accumulation, Plant Cell, 18 (2006) 3594-3605.

[91] G. Tzuri, X. Zhou, N. Chayut, H. Yuan, V. Portnoy, A. Meir, et al., A 'golden'SNP in $\mathrm{CmOr}$ governs the fruit flesh color of melon (Cucumis melo), Plant J, 82 (2015) 267-279.

[92] N. Chayut, H. Yuan, S. Ohali, A. Meir, U. Sa'ar, G. Tzuri, et al., Distinct mechanisms of the ORANGE protein in controlling carotenoid flux, Plant Physiol, 173 (2017) 376-389. 
[93] L. Li, D.J. Paolillo, M.V. Parthasarathy, E.M. DiMuzio, D.F. Garvin, A novel gene mutation that confers abnormal patterns of $\beta$-carotene accumulation in cauliflower (Brassica oleracea var. botrytis), Plant J, 26 (2001) 59-67.

[94] G. Giuliano, G. Diretto, Of chromoplasts and chaperones, Trends. Plant. Sci., 12 (2007) 529-531.

[95] X. Zhou, R. Welsch, Y. Yang, D. Álvarez, M. Riediger, H. Yuan, et al., Arabidopsis OR proteins are the major posttranscriptional regulators of phytoene synthase in controlling carotenoid biosynthesis, Proc. Natl. Acad. Sci. U. S. A., 112 (2015) 3558-3563.

[96] A. Feder, N. Chayut, A. Gur, Z. Freiman, G. Tzuri, A. Meir, et al., The Role of Carotenogenic Metabolic Flux in Carotenoid Accumulation and Chromoplast Differentiation: Lessons From the Melon Fruit, Frontiers in plant science, 10 (2019).

[97] A.B. Lopez, J. Van Eck, B.J. Conlin, D.J. Paolillo, J. O'neill, L. Li, Effect of the cauliflower Or transgene on carotenoid accumulation and chromoplast formation in transgenic potato tubers, J. Exp. Biol., 59 (2008) 213-223.

[98] H. Yuan, K. Owsiany, T. Sheeja, X. Zhou, C. Rodriguez, Y. Li, et al., A single amino acid substitution in an ORANGE protein promotes carotenoid overaccumulation in Arabidopsis, Plant Physiol, 169 (2015) 421-431.

[99] P. Schaub, M. Rodriguez-Franco, C.I. Cazzonelli, D. Álvarez, F. Wüst, R. Welsch, Establishment of an Arabidopsis callus system to study the interrelations of biosynthesis, degradation and accumulation of carotenoids, PloS one, 13 (2018) e0192158.

[100] B. Llorente, S. Torres-Montilla, L. Morelli, I. Florez-Sarasa, M. Ezquerro, L. D'ANDREA, et al., Synthetic biogenesis of chromoplasts from leaf chloroplasts, bioRxiv, (2019) 819177.

[101] J. Mi, K.-P. Jia, J.Y. Wang, S. Al-Babili, A rapid LC-MS method for qualitative and quantitative profiling of plant apocarotenoids, Anal. Chim. Acta., 1035 (2018) 87-95.

[102] J. Mi, K.-P. Jia, A. Balakrishna, J.Y. Wang, S. Al-Babili, An LC-MS profiling method reveals a route for apocarotene glycosylation and shows its induction by high light stress in Arabidopsis, Analyst, 144 (2019) 1197-1204.

[103] K. Lätari, F. Wüst, M. Hübner, P. Schaub, G.B. Kim, S. Matsubara, et al., Tissue-specific apocarotenoid glycosylation contributes to carotenoid homeostasis in Arabidopsis leaves, Plant Physiol, (2015) pp. 00243.02015.

[104] T. Ariizumi, S. Kishimoto, R. Kakami, T. Maoka, H. Hirakawa, Y. Suzuki, et al., Identification of the carotenoid modifying gene PALE YELLOW PETAL 1 as an essential factor in xanthophyll esterification and yellow flower pigmentation in tomato (Solanum lycopersicum), The Plant Journal, 79 (2014) 453-465. 
[105] H.M. Berry, D.V. Rickett, C.J. Baxter, E.M. Enfissi, P.D. Fraser, Carotenoid biosynthesis and sequestration in red chilli pepper fruit and its impact on colour intensity traits, J. Exp. Bot., 70 (2019) 2637-2650.

[106] F.T. Ahmad, D.E. Mather, H.-Y. Law, M. Li, S.A.-J. Yousif, K.J. Chalmers, et al., Genetic control of lutein esterification in wheat (Triticum aestivum L.) grain, J. Cereal Sci., 64 (2015) 109-115.

[107] C.M. Ávila, M. Palomino, D. Hornero-Méndez, S.G. Atienza, Identification of candidate genes for lutein esterification in common wheat (Triticum aestivum) using physical mapping and genomics tools, Crop. Pasture. Sci., (2019).

[108] J.L. Watkins, M. Li, R.P. McQuinn, K.X. Chan, H.E. McFarlane, M. Ermakova, et al., A GDSL Esterase/Lipase Catalyzes the Esterification of Lutein in Bread Wheat, Plant Cell, (2019) tpc. 00272.02019 .

[109] J. Kang, J.-U. Hwang, M. Lee, Y.-Y. Kim, S.M. Assmann, E. Martinoia, Y. Lee, PDR-type ABC transporter mediates cellular uptake of the phytohormone abscisic acid, Proc. Natl. Acad. Sci. U.S.A., 107 (2010) 2355-2360.

[110] Y. Kanno, A. Hanada, Y. Chiba, T. Ichikawa, M. Nakazawa, M. Matsui, et al., Identification of an abscisic acid transporter by functional screening using the receptor complex as a sensor, Proceedings of the National Academy of Sciences, 109 (2012) 9653-9658.

[111] B. Burla, S. Pfrunder, R. Nagy, R.M. Francisco, Y. Lee, E. Martinoia, Vacuolar transport of abscisic acid glucosyl ester is mediated by ATP-binding cassette and proton-antiport mechanisms in Arabidopsis, Plant Physiol., 163 (2013) 1446-1458.

[112] H. Zhang, H. Zhu, Y. Pan, Y. Yu, S. Luan, L. Li, A DTX/MATE-type transporter facilitates abscisic acid efflux and modulates ABA sensitivity and drought tolerance in Arabidopsis, Mol plant., 7 (2014) 1522-1532.

[113] T. Kretzschmar, W. Kohlen, J. Sasse, L. Borghi, M. Schlegel, J.B. Bachelier, et al., A petunia $\mathrm{ABC}$ protein controls strigolactone-dependent symbiotic signalling and branching, Nature, 483 (2012) 341.

[114] O.C. Demurtas, R. de Brito Francisco, G. Diretto, P. Ferrante, S. Frusciante, M. Pietrella, et al., ABCC transporters mediate the vacuolar accumulation of crocins in saffron stigmas, Plant Cell, 31 (2019) 2789-2804.

[115] P. Schaub, F. Wüst, J. Koschmieder, Q. Yu, P. Virk, J. Tohme, P. Beyer, Nonenzymatic $\beta$-carotene degradation in provitamin A-biofortified crop plants, J. Agric. Food Chem., 65 (2017) 6588-6598.

[116] M. Jarén-Galán, M.I. Mínguez-Mosquera, Effect of pepper lipoxygenase activity and its 
linked reactions on pigments of the pepper fruit, J. Agric. Food Chem., 47 (1999) 4532-4536.

[117] D. Gayen, N. Ali, S.N. Sarkar, S.K. Datta, K. Datta, Down-regulation of lipoxygenase gene reduces degradation of carotenoids of golden rice during storage, Planta, 242 (2015) 353-363.

[118] A. Carrera, V. Echenique, W. Zhang, M. Helguera, F. Manthey, A. Schrager, et al., A deletion at the $L p x-B 1$ locus is associated with low lipoxygenase activity and improved pasta color in durum wheat (Triticum turgidum ssp. durum), J. Cereal Sci., 45 (2007) 67-77.

[119] L. Gao, I. Gonda, H. Sun, Q. Ma, K. Bao, D.M. Tieman, et al., The tomato pan-genome uncovers new genes and a rare allele regulating fruit flavor, Nat. Genet., 51 (2019) 1044.

[120] O. Ahrazem, L. Gómez-Gómez, M.J. Rodrigo, J. Avalos, M.C. Limón, Carotenoid cleavage oxygenases from microbes and photosynthetic organisms: features and functions, Int. J. Mol. Sci., 17 (2016) 1781.

[121] J. von Lintig, K. Vogt, Filling the gap in vitamin a research molecular identification of an enzyme cleaving $\beta$-carotene to retinal, J. Biol. Chem., 275 (2000) 11915-11920.

[122] J. von Lintig, Provitamin A metabolism and functions in mammalian biology, Am. J. Clin. Nutr., 96 (2012) 1234S-1244S.

[123] P.D. Kiser, K. Palczewski, Retinoids and retinal diseases, Annu. Rev. Vis. Sci., 2 (2016) 197-234.

[124] B.-C. Tan, L.M. Joseph, W.-T. Deng, L. Liu, Q.-B. Li, K. Cline, D.R. McCarty, Molecular characterization of theArabidopsis9-cisepoxycarotenoid dioxygenase gene family, Plant J, 35 (2003) 44-56.

[125] A. Ilg, P. Beyer, S. Al-Babili, Characterization of the rice carotenoid cleavage dioxygenase 1 reveals a novel route for geranial biosynthesis, FEBS J., 276 (2009) 736-747.

[126] A. Ilg, M. Bruno, P. Beyer, S. Al-Babili, Tomato carotenoid cleavage dioxygenases 1A and 1B: relaxed double bond specificity leads to a plenitude of dialdehydes, mono-apocarotenoids and isoprenoid volatiles, FEBS Open Bio, 4 (2014) 584-593.

[127] S.H. Schwartz, X. Qin, J.A. Zeevaart, Characterization of a novel carotenoid cleavage dioxygenase from plants, J. Biol. Chem., 276 (2001) 25208-25211.

[128] J.T. Vogel, B.-C. Tan, D.R. McCarty, H.J. Klee, The carotenoid cleavage dioxygenase 1 enzyme has broad substrate specificity, cleaving multiple carotenoids at two different bond positions, J. Biol. Chem., 283 (2008) 11364-11373.

[129] M.E. Auldridge, A. Block, J.T. Vogel, C. Dabney-Smith, I. Mila, M. Bouzayen, et al., Characterization of three members of the Arabidopsis carotenoid cleavage dioxygenase family demonstrates the divergent roles of this multifunctional enzyme family, Plant J, 45 (2006) 
982-993.

[130] A.J. Simkin, S.H. Schwartz, M. Auldridge, M.G. Taylor, H.J. Klee, The tomato carotenoid cleavage dioxygenase 1 genes contribute to the formation of the flavor volatiles $\beta$-ionone, pseudoionone, and geranylacetone, Plant J, 40 (2004) 882-892.

[131] A.J. Simkin, B.A. Underwood, M. Auldridge, H.M. Loucas, K. Shibuya, E. Schmelz, et al., Circadian regulation of the PhCCD1 carotenoid cleavage dioxygenase controls emission of $\beta$-ionone, a fragrance volatile of petunia flowers, Plant Physiol, 136 (2004) 3504-3514.

[132] S. Frusciante, G. Diretto, M. Bruno, P. Ferrante, M. Pietrella, A. Prado-Cabrero, et al., Novel carotenoid cleavage dioxygenase catalyzes the first dedicated step in saffron crocin biosynthesis, Proc. Natl. Acad. Sci. U. S. A., 111 (2014) 12246-12251.

[133] O. Ahrazem, A. Rubio-Moraga, J. Berman, T. Capell, P. Christou, C. Zhu, L. GómezGómez, The carotenoid cleavage dioxygenase CCD2 catalysing the synthesis of crocetin in spring crocuses and saffron is a plastidial enzyme, New Phytol, 209 (2016) 650-663.

[134] O.C. Demurtas, S. Frusciante, P. Ferrante, G. Diretto, N.H. Azad, M. Pietrella, et al., Candidate enzymes for saffron crocin biosynthesis are localized in multiple cellular compartments, Plant Physiol, 177 (2018) 990-1006.

[135] G. Diretto, O. Ahrazem, Á. Rubio-Moraga, A. Fiore, F. Sevi, J. Argandoña, L. GómezGómez, UGT709G1: a novel uridine diphosphate glycosyltransferase involved in the biosynthesis of picrocrocin, the precursor of safranal in saffron (Crocus sativus), New Phytol, (2019).

[136] M. Bruno, J. Koschmieder, F. Wuest, P. Schaub, M. Fehling-Kaschek, J. Timmer, et al., Enzymatic study on AtCCD4 and AtCCD7 and their potential to form acyclic regulatory metabolites, J. Exp. Biol., 67 (2016) 5993-6005.

[137] J. Mi, S. Al-Babili, To Color or to Decolor: that Is the Question, Mol. Plant., 12 (2019) 1173-1175.

[138] M. Bruno, P. Beyer, S. Al-Babili, The potato carotenoid cleavage dioxygenase 4 catalyzes a single cleavage of $\beta$-ionone ring-containing carotenes and non-epoxidated xanthophylls, Arch. Biochem. Biophys., 572 (2015) 126-133.

[139] G. Ma, L. Zhang, A. Matsuta, K. Matsutani, K. Yamawaki, M. Yahata, et al., Enzymatic formation of beta-citraurin from beta-cryptoxanthin and Zeaxanthin by carotenoid cleavage dioxygenase4 in the flavedo of citrus fruit, Plant Physiol, 163 (2013) 682-695.

[140] M.J. Rodrigo, B. Alquezar, E. Alos, V. Medina, L. Carmona, M. Bruno, et al., A novel carotenoid cleavage activity involved in the biosynthesis of Citrus fruit-specific apocarotenoid pigments, J. Exp. Bot., 64 (2013) 4461-4478.

[141] X. Zheng, K. Zhu, Q. Sun, W. Zhang, X. Wang, H. Cao, et al., Natural Variation in CCD4 
Promoter Underpins Species-specific Evolution of Red Coloration in Citrus Peel, Mol. Plant., (2019).

[142] X. Zheng, Z. Xie, K. Zhu, Q. Xu, X. Deng, Z. Pan, Isolation and characterization of carotenoid cleavage dioxygenase 4 genes from different citrus species, Mol. Genet. Genomics., 290 (2015) 1589-1603.

[143] O. Ahrazem, G. Diretto, J. Argandoña, Á. Rubio-Moraga, J.M. Julve, D. Orzáez, et al., Evolutionarily distinct carotenoid cleavage dioxygenases are responsible for crocetin production in Buddleja davidii, J. Exp. Biol., 68 (2017) 4663-4677.

[144] A. Alder, M. Jamil, M. Marzorati, M. Bruno, M. Vermathen, P. Bigler, et al., The path from $\beta$-carotene to carlactone, a strigolactone-like plant hormone, Science, 335 (2012) 1348-1351.

[145] M. Bruno, M. Hofmann, M. Vermathen, A. Alder, P. Beyer, S. Al-Babili, On the substrate-and stereospecificity of the plant carotenoid cleavage dioxygenase 7, FEBS Lett., 588 (2014) 1802-1807.

[146] M. Bruno, S. Al-Babili, On the substrate specificity of the rice strigolactone biosynthesis enzyme DWARF27, Planta, 243 (2016) 1429-1440.

[147] H. Abuauf, I. Haider, K.-P. Jia, A. Ablazov, J. Mi, I. Blilou, S. Al-Babili, The Arabidopsis DWARF27 gene encodes an all-trans-/9-cis- $\beta$-carotene isomerase and is induced by auxin, abscisic acid and phosphate deficiency, Plant Sci., 277 (2018) 33-42.

[148] M. Bruno, M. Vermathen, A. Alder, F. Wüst, P. Schaub, R. van der Steen, et al., Insights into the formation of carlactone from in-depth analysis of the CCD 8-catalyzed reactions, FEBS Lett., 591 (2017) 792-800.

[149] A. Alder, I. Holdermann, P. Beyer, S. Al-Babili, Carotenoid oxygenases involved in plant branching catalyse a highly specific conserved apocarotenoid cleavage reaction, Biochem. J., 416 (2008) 289-296.

[150] Y. Zhang, A.D. Van Dijk, A. Scaffidi, G.R. Flematti, M. Hofmann, T. Charnikhova, et al., Rice cytochrome P450 MAX1 homologs catalyze distinct steps in strigolactone biosynthesis, Nat. Chem. Biol., 10 (2014) 1028.

[151] S. Abe, A. Sado, K. Tanaka, T. Kisugi, K. Asami, S. Ota, et al., Carlactone is converted to carlactonoic acid by MAX1 in Arabidopsis and its methyl ester can directly interact with AtD14 in vitro, Proc. Natl. Acad. Sci. U. S. A., 111 (2014) 18084-18089.

[152] R. Falchi, E. Vendramin, L. Zanon, S. Scalabrin, G. Cipriani, I. Verde, et al., Three distinct mutational mechanisms acting on a single gene underpin the origin of yellow flesh in peach, Plant J, 76 (2013) 175-187.

[153] R. Campbell, L.J. Ducreux, W.L. Morris, J.A. Morris, J.C. Suttle, G. Ramsay, et al., The 
metabolic and developmental roles of carotenoid cleavage dioxygenase4 from potato, Plant Physiol, 154 (2010) 656-664.

[154] S. Gonzalez-Jorge, S.H. Ha, M. Magallanes-Lundback, L.U. Gilliland, A. Zhou, A.E. Lipka, et al., Carotenoid cleavage dioxygenase 4 is a negative regulator of beta-carotene content in Arabidopsis seeds, Plant Cell, 25 (2013) 4812-4826.

[155] A. Ohmiya, S. Kishimoto, R. Aida, S. Yoshioka, K. Sumitomo, Carotenoid cleavage dioxygenase (CmCCD4a) contributes to white color formation in chrysanthemum petals, Plant Physiol, 142 (2006) 1193-1201.

[156] B. Zhang, C. Liu, Y. Wang, X. Yao, F. Wang, J. Wu, et al., Disruption of a CAROTENOID CLEAVAGE DIOXYGENASE 4 gene converts flower colour from white to yellow in Brassica species, New Phytol, 206 (2015) 1513-1526.

[157] F. Han, H. Cui, B. Zhang, X. Liu, L. Yang, M. Zhuang, et al., Map-based cloning and characterization of $B o C C D 4$, a gene responsible for white/yellow petal color in B. oleracea, BMC genomics, 20 (2019) 242.

[158] F. Brandi, E. Bar, F. Mourgues, G. Horváth, E. Turcsi, G. Giuliano, et al., Study of'Redhaven'peach and its white-fleshed mutant suggests a key role of CCD4 carotenoid dioxygenase in carotenoid and norisoprenoid volatile metabolism, BMC Plant Biol., 11 (2011) 24.

[159] K. Watanabe, C. Oda-Yamamizo, K. Sage-Ono, A. Ohmiya, M. Ono, Alteration of flower colour in Ipomoea nil through CRISPR/Cas9-mediated mutagenesis of carotenoid cleavage dioxygenase 4, Transgenic Res., 27 (2018) 25-38.

[160] N.H. Bhuiyan, G. Friso, E. Rowland, K. Majsec, K.J. van Wijk, The plastoglobule-localized metallopeptidase PGM48 is a positive regulator of senescence in Arabidopsis thaliana, Plant Cell, 28 (2016) 3020-3037.

[161] A. Ilg, Q. Yu, P. Schaub, P. Beyer, S. Al-Babili, Overexpression of the rice carotenoid cleavage dioxygenase 1 gene in Golden Rice endosperm suggests apocarotenoids as substrates in planta, Planta, 232 (2010) 691-699.

[162] R. Welsch, F. Wüst, C. Bär, S. Al-Babili, P. Beyer, A third phytoene synthase is devoted to abiotic stress-induced abscisic acid formation in rice and defines functional diversification of phytoene synthase genes, Plant Physiol, 147 (2008) 367-380.

[163] F. Li, R. Vallabhaneni, E.T. Wurtzel, PSY3, a new member of the phytoene synthase gene family conserved in the Poaceae and regulator of abiotic stress-induced root carotenogenesis, Plant Physiol, 146 (2008) 1333-1345.

[164] T. Sun, L. Li, Toward the 'golden'era: the status in uncovering the regulatory control of carotenoid accumulation in plants, Plant Sci., (2019) 110331. 
[165] L. Stanley, Y.-W. Yuan, Transcriptional regulation of carotenoid biosynthesis in plants: So many regulators, so little consensus, Front. Plant Sci., 10 (2019) 1017.

[166] G. Toledo-Ortiz, H. Johansson, K.P. Lee, J. Bou-Torrent, K. Stewart, G. Steel, et al., The HY5-PIF regulatory module coordinates light and temperature control of photosynthetic gene transcription, PLoS Genet., 10 (2014) e1004416.

[167] R. Welsch, D. Maass, T. Voegel, D. DellaPenna, P. Beyer, Transcription factor RAP2. 2 and its interacting partner SINAT2: stable elements in the carotenogenesis of Arabidopsis leaves, Plant Physiol, 145 (2007) 1073-1085.

[168] M. Zhu, G. Chen, J. Zhang, Y. Zhang, Q. Xie, Z. Zhao, et al., The abiotic stress-responsive NAC-type transcription factor SINAC4 regulates salt and drought tolerance and stress-related genes in tomato (Solanum lycopersicum), Plant Cell Rep., 33 (2014) 1851-1863.

[169] N. Ma, H. Feng, X. Meng, D. Li, D. Yang, C. Wu, Q. Meng, Overexpression of tomato SINACl transcription factor alters fruit pigmentation and softening, BMC Plant Biol., 14 (2014) 351.

[170] C. Meng, D. Yang, X. Ma, W. Zhao, X. Liang, N. Ma, Q. Meng, Suppression of tomato SlNACl transcription factor delays fruit ripening, J. Plant Physiol., 193 (2016) 88-96.

[171] M. Fujisawa, T. Nakano, Y. Shima, Y. Ito, A large-scale identification of direct targets of the tomato MADS box transcription factor RIPENING INHIBITOR reveals the regulation of fruit ripening, Plant Cell, 25 (2013) 371-386.

[172] C. Xiong, D. Luo, A. Lin, C. Zhang, L. Shan, P. He, et al., A tomato B-box protein S1 BBX 20 modulates carotenoid biosynthesis by directly activating PHYTOENE SYNTHASE 1 , and is targeted for 26S proteasome-mediated degradation, New Phytol, 221 (2019) 279-294.

[173] C. Ampomah-Dwamena, A.H. Thrimawithana, S. Dejnoprat, D. Lewis, R.V. Espley, A.C. Allan, A kiwifruit (Actinidia deliciosa) R2R3-MYB transcription factor modulates chlorophyll and carotenoid accumulation, New Phytol, 221 (2019) 309-325.

[174] S. Lu, Y. Zhang, K. Zhu, W. Yang, J. Ye, L. Chai, et al., The citrus transcription factor CsMADS6 modulates carotenoid metabolism by directly regulating carotenogenic genes, Plant Physiol, 176 (2018) 2657-2676.

[175] J. Arango, M. Jourdan, E. Geoffriau, P. Beyer, R. Welsch, Carotene hydroxylase activity determines the levels of both $\alpha$-carotene and total carotenoids in orange carrots, Plant Cell, 26 (2014) 2223-2233.

[176] V. Corona, B. Aracri, G. Kosturkova, G.E. Bartley, L. Pitto, L. Giorgetti, et al., Regulation of a carotenoid biosynthesis gene promoter during plant development, Plant J, 9 (1996) 505-512.

[177] C.I. Cazzonelli, A.J. Cuttriss, S.B. Cossetto, W. Pye, P. Crisp, J. Whelan, et al., Regulation of carotenoid composition and shoot branching in Arabidopsis by a chromatin modifying histone 
methyltransferase, SDG8, Plant Cell, 21 (2009) 39-53.

[178] R. Welsch, X. Zhou, H. Yuan, D. Álvarez, T. Sun, D. Schlossarek, et al., Clp protease and OR directly control the proteostasis of phytoene synthase, the crucial enzyme for carotenoid biosynthesis in Arabidopsis, Mol. Plant., 11 (2018) 149-162.

[179] J.E. Bailey, A. Sburlati, V. Hatzimanikatis, K. Lee, W.A. Renner, P.S. Tsai, Inverse metabolic engineering: a strategy for directed genetic engineering of useful phenotypes, Biotechnol. Bioeng., 79 (2002) 568-579.

[180] D.J. Kliebenstein, Synthetic biology of metabolism: using natural variation to reverse engineer systems, Curr. Opin. Biotechnol., 19 (2014) 20-26.

[181] R. Vallabhaneni, C.E. Gallagher, N. Licciardello, A.J. Cuttriss, R.F. Quinlan, E.T. Wurtzel, Metabolite sorting of a germplasm collection reveals the hydroxylase 3 locus as a new target for maize provitamin A biofortification, Plant Physiol, 151 (2009) 1635-1645.

[182] J. Yan, C.B. Kandianis, C.E. Harjes, L. Bai, E.H. Kim, X. Yang, et al., Rare genetic variation at Zea mays crtRB1 increases beta-carotene in maize grain, Nat Genet., 42 (2010) 322-327.

[183] C.E. Harjes, T.R. Rocheford, L. Bai, T.P. Brutnell, C.B. Kandianis, S.G. Sowinski, et al., Natural genetic variation in lycopene epsilon cyclase tapped for maize biofortification, Science, 319 (2008) 330-333.

[184] J. Wong, R. Lambert, E. Wurtzel, T. Rocheford, QTL and candidate genes phytoene synthase and $\zeta$-carotene desaturase associated with the accumulation of carotenoids in maize, Theor. Appl. Genet., 108 (2004) 349-359.

[185] R.U. Zunjare, F. Hossain, V. Muthusamy, A. Baveja, H.S. Chauhan, J.S. Bhat, et al., Development of biofortified maize hybrids through marker-assisted stacking of $\beta$-carotene

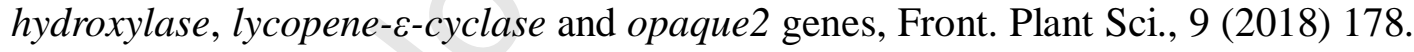

[186] R. Welsch, J. Arango, C. Bär, B. Salazar, S. Al-Babili, J. Beltrán, et al., Provitamin A accumulation in cassava (Manihot esculenta) roots driven by a single nucleotide polymorphism in a phytoene synthase gene, Plant Cell, (2010) tpc. 110.077560.

[187] H. Cao, H. Luo, H. Yuan, M.A. Eissa, T.W. Thannhauser, R. Welsch, et al., A neighboring aromatic-aromatic amino acid combination governs activity divergence between tomato phytoene synthases, Plant Physiol, 180 (2019) 1988-2003.

[188] J.A. Paine, C.A. Shipton, S. Chaggar, R.M. Howells, M.J. Kennedy, G. Vernon, et al., Improving the nutritional value of Golden Rice through increased pro-vitamin A content, Nat. Biotechnol., 23 (2005) 482.

[189] A.C. Komor, Y.B. Kim, M.S. Packer, J.A. Zuris, D.R. Liu, Programmable editing of a 
target base in genomic DNA without double-stranded DNA cleavage, Nature, 533 (2016) 420.

[190] P.W. Simon, Domestication, historical development, and modern breeding of carrot, Plant Breed. Rev.,, 19 (2000) 157-190.

[191] B.J. Just, C.A. Santos, B.S. Yandell, P.W. Simon, Major QTL for carrot color are positionally associated with carotenoid biosynthetic genes and interact epistatically in a domesticated× wild carrot cross, Theor. Appl. Genet., 119 (2009) 1155-1169.

[192] M. Iorizzo, S. Ellison, D. Senalik, P. Zeng, P. Satapoomin, J. Huang, et al., A high-quality carrot genome assembly provides new insights into carotenoid accumulation and asterid genome evolution, Nat Genet., 48 (2016) 657-666.

[193] S.L. Ellison, C.H. Luby, K.E. Corak, K.M. Coe, D. Senalik, M. Iorizzo, et al., Carotenoid presence is associated with the Or gene in domesticated carrot, Genetics, 210 (2018) 1497-1508.

[194] A.-M.A. Wolters, J.G. Uitdewilligen, B.A. Kloosterman, R.C. Hutten, R.G. Visser, H.J. van Eck, Identification of alleles of carotenoid pathway genes important for zeaxanthin accumulation in potato tubers, Plant Mol. Biol., 73 (2010) 659-671.

[195] S. Gonzalez-Jorge, P. Mehrshahi, M. Magallanes-Lundback, A.E. Lipka, R. Angelovici, M.A. Gore, D. DellaPenna, ZEAXANTHIN EPOXIDASE activity potentiates carotenoid degradation in maturing seed, Plant Physiol, 171 (2016) 1837-1851.

[196] A. Endo, H. Saika, M. Takemura, N. Misawa, S. Toki, A novel approach to carotenoid accumulation in rice callus by mimicking the cauliflower Orange mutation via genome editing, Rice, 12 (2019) 1-5.

[197] D. Richaud, C. Stange, A. Gadaleta, P. Colasuonno, R. Parada, A.R. Schwember, Identification of Lycopene epsilon cyclase (LCYE) gene mutants to potentially increase $\beta$-carotene content in durum wheat (Triticum turgidum L. ssp. durum) through TILLING, PloS one, 13 (2018) e0208948.

[198] J.Y. Paul, H. Khanna, J. Kleidon, P. Hoang, J. Geijskes, J. Daniells, et al., Golden bananas in the field: elevated fruit pro-vitamin A from the expression of a single banana transgene, Plant Biotechnol. J., 15 (2017) 520-532.

[199] P.D. Fraser, E.M. Enfissi, J.M. Halket, M.R. Truesdale, D. Yu, C. Gerrish, P.M. Bramley, Manipulation of phytoene levels in tomato fruit: effects on isoprenoids, plastids, and intermediary metabolism, Plant Cell, 19 (2007) 3194-3211.

[200] P.K. Burkhardt, P. Beyer, J. Wünn, A. Klöti, G.A. Armstrong, M. Schledz, et al., Transgenic rice (Oryza sativa) endosperm expressing daffodil (Narcissus pseudonarcissus) phytoene synthase accumulates phytoene, a key intermediate of provitamin A biosynthesis, Plant J, 11 (1997) 1071-1078. 
[201] R.P. McQuinn, B. Wong, J.J. Giovannoni, AtPDS overexpression in tomato: exposing unique patterns of carotenoid self-regulation and an alternative strategy for the enhancement of fruit carotenoid content, Plant Biotechnol. J., 16 (2018) 482-494.

[202] R.G. Fray, A. Wallace, P.D. Fraser, D. Valero, P. Hedden, P.M. Bramley, D. Grierson, Constitutive expression of a fruit phytoene synthase gene in transgenic tomatoes causes dwarfism by redirecting metabolites from the gibberellin pathway, Plant J, 8 (1995) 693-701.

[203] M. Busch, A. Seuter, R. Hain, Functional analysis of the early steps of carotenoid biosynthesis in tobacco, Plant Physiol, 128 (2002) 439-453.

[204] A. Masferrer, M. Arró, D. Manzano, H. Schaller, X. Fernández-Busquets, P. Moncaleán, et al., Overexpression of Arabidopsis thaliana farnesyl diphosphate synthase (FPS1S) in transgenic Arabidopsis induces a cell death/senescence-like response and reduced cytokinin levels, Plant J, 30 (2002) 123-132.

[205] M. Nogueira, E.M. Enfissi, J. Almeida, P.D. Fraser, Creating plant molecular factories for industrial and nutritional isoprenoid production, Curr. Opin. Biotechnol., 49 (2018) 80-87.

[206] P. Davison, C. Hunter, P. Horton, Overexpression of $\beta$-carotene hydroxylase enhances stress tolerance in Arabidopsis, Nature, 418 (2002) 203.

[207] Q. Zhao, G. Wang, J. Ji, C. Jin, W. Wu, J. Zhao, Over-expression of Arabidopsis thaliana $\beta$-carotene hydroxylase (chyB) gene enhances drought tolerance in transgenic tobacco, Journal of plant biochemistry and biotechnology, 23 (2014) 190-198.

[208] C. D’Ambrosio, G. Giorio, I. Marino, A. Merendino, A. Petrozza, L. Salfi, et al., Virtually complete conversion of lycopene into $\beta$-carotene in fruits of tomato plants transformed with the tomato lycopene $\beta$-cyclase (tlcy-b) cDNA, Plant Science, 166 (2004) 207-214.

[209] G. Diretto, S. Frusciante, C. Fabbri, N. Schauer, L. Busta, Z. Wang, et al., Manipulation of $\beta$-carotene levels in tomato fruits results in increased ABA content and extended shelf-life, Plant biotechnology journal, (2019).

[210] T. Sánchez, A.L. Chávez, H. Ceballos, D.B. Rodriguez-Amaya, P. Nestel, M. Ishitani, Reduction or delay of post-harvest physiological deterioration in cassava roots with higher carotenoid content, Journal of the Science of Food and Agriculture, 86 (2006) 634-639.

[211] C.K. Shewmaker, J.A. Sheehy, M. Daley, S. Colburn, D.Y. Ke, Seed-specific overexpression of phytoene synthase: increase in carotenoids and other metabolic effects, Plant J, 20 (1999) 401-412.

[212] D. Yao, Y. Wang, Q. Li, X. Ouyang, Y. Li, C. Wang, et al., Specific upregulation of a cotton phytoene synthase gene produces golden cottonseeds with enhanced provitamin A, Sci. Rep., 8 (2018) 1348. 
[213] W.L. Morris, L.J. Ducreux, P. Hedden, S. Millam, M.A. Taylor, Overexpression of a bacterial 1-deoxy-D-xylulose 5-phosphate synthase gene in potato tubers perturbs the isoprenoid metabolic network: implications for the control of the tuber life cycle, J. Exp. Biol., 57 (2006) 3007-3018.

[214] E.M. Enfissi, P.D. Fraser, L.M. Lois, A. Boronat, W. Schuch, P.M. Bramley, Metabolic engineering of the mevalonate and non-mevalonate isopentenyl diphosphate-forming pathways for the production of health-promoting isoprenoids in tomato, Plant Biotechnol. J., 3 (2005) $17-27$.

[215] X. Ye, S. Al-Babili, A. Klöti, J. Zhang, P. Lucca, P. Beyer, I. Potrykus, Engineering the provitamin A ( $\beta$-carotene) biosynthetic pathway into (carotenoid-free) rice endosperm, Science, 287 (2000) 303-305.

[216] K. Datta, N. Baisakh, N. Oliva, L. Torrizo, E. Abrigo, J. Tan, et al., Bioengineered 'golden'indica rice cultivars with $\beta$-carotene metabolism in the endosperm with hygromycin and mannose selection systems, Plant Biotechnol. J., 1 (2003) 81-90.

[217] S. Al-Babili, T.T.C. Hoa, P. Schaub, Exploring the potential of the bacterial carotene desaturase CrtI to increase the $\beta$-carotene content in Golden Rice, J. Exp. Biol., 57 (2006) 1007-1014.

[218] P. Schaub, S. Al-Babili, R. Drake, P. Beyer, Why is golden rice golden (yellow) instead of red?, Plant Physiol, 138 (2005) 441-450.

[219] M.P. Ravanello, D. Ke, J. Alvarez, B. Huang, C.K. Shewmaker, Coordinate expression of multiple bacterial carotenoid genes in canola leading to altered carotenoid production, Metab. Eng., 5 (2003) 255-263.

[220] C. Wang, J. Zeng, Y. Li, W. Hu, L. Chen, Y. Miao, et al., Enrichment of provitamin A content in wheat (Triticum aestivum L.) by introduction of the bacterial carotenoid biosynthetic genes $C r t B$ and $C r t I$, J. Exp. Biol., 65 (2014) 2545-2556.

[221] G. Diretto, S. Al-Babili, R. Tavazza, V. Papacchioli, P. Beyer, G. Giuliano, Metabolic engineering of potato carotenoid content through tuber-specific overexpression of a bacterial mini-pathway, PLoS One, 2 (2007) e350.

[222] M. Fujisawa, E. Takita, H. Harada, N. Sakurai, H. Suzuki, K. Ohyama, et al., Pathway engineering of Brassica napus seeds using multiple key enzyme genes involved in ketocarotenoid formation, J. Exp. Biol., 60 (2009) 1319-1332.

[223] Q. Zhu, D. Zeng, S. Yu, C. Cui, J. Li, H. Li, et al., From Golden Rice to aSTARice: bioengineering astaxanthin biosynthesis in rice endosperm, Mol. Plant., 11 (2018) 1440-1448.

[224] C. Zhu, S. Naqvi, J. Breitenbach, G. Sandmann, P. Christou, T. Capell, Combinatorial genetic transformation generates a library of metabolic phenotypes for the carotenoid pathway in 
maize, Proc. Natl. Acad. Sci. U. S. A., 105 (2008) 18232-18237.

[225] M.L. Donnelly, G. Luke, A. Mehrotra, X. Li, L.E. Hughes, D. Gani, M.D. Ryan, Analysis of the aphthovirus $2 \mathrm{~A} / 2 \mathrm{~B}$ polyprotein 'cleavage'mechanism indicates not a proteolytic reaction, but a novel translational effect: a putative ribosomal 'skip', J. Gen. Virol., 82 (2001) 1013-1025.

[226] L. Ralley, E.M. Enfissi, N. Misawa, W. Schuch, P.M. Bramley, P.D. Fraser, Metabolic engineering of ketocarotenoid formation in higher plants, Plant J, 39 (2004) 477-486.

[227] S.H. Ha, Y.S. Liang, H. Jung, M.J. Ahn, S.C. Suh, S.J. Kweon, et al., Application of two bicistronic systems involving $2 \mathrm{~A}$ and IRES sequences to the biosynthesis of carotenoids in rice endosperm, Plant Biotechnol. J., 8 (2010) 928-938.

[228] M. Camagna, A. Grundmann, C. Bär, J. Koschmieder, P. Beyer, R. Welsch, Enzyme fusion removes competition for geranylgeranyl diphosphate in carotenogenesis, Plant Physiol, 179 (2019) 1013-1027.

[229] S.-H. Ha, J.K. Kim, Y.S. Jeong, M.-K. You, S.-H. Lim, J.-K. Kim, Stepwise pathway engineering to the biosynthesis of zeaxanthin, astaxanthin and capsanthin in rice endosperm, Metab. Eng., 52 (2019) 178-189.

[230] T. Hasunuma, S.I. Miyazawa, S. Yoshimura, Y. Shinzaki, K.I. Tomizawa, K. Shindo, et al., Biosynthesis of astaxanthin in tobacco leaves by transplastomic engineering, Plant J, 55 (2008) 857-868.

[231] H. Harada, T. Maoka, A. Osawa, J.-i. Hattan, H. Kanamoto, K. Shindo, et al., Construction of transplastomic lettuce (Lactuca sativa) dominantly producing astaxanthin fatty acid esters and detailed chemical analysis of generated carotenoids, Transgenic Res., 23 (2014) 303-315.

[232] S. Kumar, F.M. Hahn, E. Baidoo, T.S. Kahlon, D.F. Wood, C.M. McMahan, et al., Remodeling the isoprenoid pathway in tobacco by expressing the cytoplasmic mevalonate pathway in chloroplasts, Metab. Eng., 14 (2012) 19-28.

[233] S.-Y. Kwak, T.T.S. Lew, C.J. Sweeney, V.B. Koman, M.H. Wong, K. Bohmert-Tatarev, et al., Chloroplast-selective gene delivery and expression in planta using chitosan-complexed single-walled carbon nanotube carriers, Nat. Nanotechnol., 14 (2019) 447.

[234] K. Watanabe, C. Oda-Yamamizo, K. Sage-Ono, A. Ohmiya, M. Ono, Alteration of flower colour in Ipomoea nil through CRISPR/Cas9-mediated mutagenesis of carotenoid cleavage dioxygenase 4, Transgenic research, 27 (2018) 25-38.

[235] S. Bai, P.A. Tuan, M. Tatsuki, H. Yaegaki, A. Ohmiya, C. Yamamizo, T. Moriguchi, Knockdown of carotenoid cleavage dioxygenase 4 (CCD4) via virus-induced gene silencing confers yellow coloration in peach fruit: evaluation of gene function related to fruit traits, Plant Mol. Biol. Rep., 34 (2016) 257-264.

[236] A. Ohmiya, K. Sumitomo, R. Aida, "Yellow Jimba": Suppression of carotenoid cleavage 
dioxygenase $(\mathrm{CmCCD} 4 a)$ expression turns white chrysanthemum petals yellow, J. Jpn. Soc. Hortic. Sci., 78 (2009) 450-455.

[237] C. Rosati, R. Aquilani, S. Dharmapuri, P. Pallara, C. Marusic, R. Tavazza, et al., Metabolic engineering of beta-carotene and lycopene content in tomato fruit, Plant J, 24 (2000) 413-420.

[238] S. Römer, J. Lübeck, F. Kauder, S. Steiger, C. Adomat, G. Sandmann, Genetic engineering of a zeaxanthin-rich potato by antisense inactivation and co-suppression of carotenoid epoxidation, Metab. Eng., 4 (2002) 263-272.

[239] G. Diretto, R. Tavazza, R. Welsch, D. Pizzichini, F. Mourgues, V. Papacchioli, et al., Metabolic engineering of potato tuber carotenoids through tuber-specific silencing of lycopene epsilon cyclase, BMC Plant Biol., 6 (2006) 13.

[240] E. Pons, B. Alquézar, A. Rodríguez, P. Martorell, S. Genovés, D. Ramón, et al., Metabolic engineering of $\beta$-carotene in orange fruit increases its in vivo antioxidant properties, Plant Biotechnol. J., 12 (2014) 17-27.

[241] J. Zeng, X. Wang, Y. Miao, C. Wang, M. Zang, X. Chen, et al., Metabolic engineering of wheat provitamin A by simultaneously overexpressing $\mathrm{CrtB}$ and silencing carotenoid hydroxylase (TaHYD), J. Agric. Food Chem., 63 (2015) 9083-9092.

[242] G. Farré, L. Perez-Fons, M. Decourcelle, J. Breitenbach, S. Hem, C. Zhu, et al., Metabolic engineering of astaxanthin biosynthesis in maize endosperm and characterization of a prototype high oil hybrid, Transgenic Res., 25 (2016) 477-489.

[243] L. Li, J. Van Eck, Metabolic engineering of carotenoid accumulation by creating a metabolic sink, Transgenic Res., 16 (2007) 581-585.

[244] L. Li, Y. Yang, Q. Xu, K. Owsiany, R. Welsch, C. Chitchumroonchokchai, et al., The Or gene enhances carotenoid accumulation and stability during post-harvest storage of potato tubers, Mol. Plant., 5 (2012) 339-352.

[245] J. Berman, U. Zorrilla-López, V. Medina, G. Farré, G. Sandmann, T. Capell, et al., The Arabidopsis ORANGE (AtOR) gene promotes carotenoid accumulation in transgenic corn hybrids derived from parental lines with limited carotenoid pools, Plant Cell Rep., 36 (2017) 933-945.

[246] M. Yazdani, Z. Sun, H. Yuan, S. Zeng, T.W. Thannhauser, J. Vrebalov, et al., Ectopic expression of ORANGE promotes carotenoid accumulation and fruit development in tomato, Plant Biotechnol. J., 17 (2019) 33-49.

[247] G.R. Davuluri, A. Van Tuinen, P.D. Fraser, A. Manfredonia, R. Newman, D. Burgess, et al., Fruit-specific RNAi-mediated suppression of DET1 enhances carotenoid and flavonoid content in tomatoes, Nat. Biotechnol., 23 (2005) 890. 
[248] E.M. Enfissi, F. Barneche, I. Ahmed, C. Lichtlé, C. Gerrish, R.P. McQuinn, et al., Integrative transcript and metabolite analysis of nutritionally enhanced DE-ETIOLATED1 downregulated tomato fruit, Plant Cell, 22 (2010) 1190-1215.

[249] N. Galpaz, Q. Wang, N. Menda, D. Zamir, J. Hirschberg, Abscisic acid deficiency in the tomato mutant high-pigment 3 leading to increased plastid number and higher fruit lycopene content, Plant J, 53 (2008) 717-730.

[250] T. Ariizumi, S. Kishimoto, R. Kakami, T. Maoka, H. Hirakawa, Y. Suzuki, et al., Identification of the carotenoid modifying gene PALE YELLOW PETAL 1 as an essential factor in xanthophyll esterification and yellow flower pigmentation in tomato (Solanum lycopersicum), Plant J, 79 (2014) 453-465.

[251] G. Ma, L. Zhang, K. Iida, Y. Madono, W. Yungyuen, M. Yahata, et al., Identification and quantitative analysis of $\beta$-cryptoxanthin and $\beta$-citraurin esters in Satsuma mandarin fruit during the ripening process, Food Chem., 234 (2017) 356-364.

[252] E. Mellado-Ortega, D. Hornero-Méndez, Lutein esterification in wheat flour increases the carotenoid retention and is induced by storage temperatures, Foods, 6 (2017) 111.

[253] E. Mellado-Ortega, D. Hornero-Méndez, Effect of lutein esterification on the differential distribution of carotenoids in germ and endosperm fractions from tritordeum grains, J. Cereal Sci., 79 (2018) 462-468.

[254] P. Che, Z.-Y. Zhao, K. Glassman, D. Dolde, T.X. Hu, T.J. Jones, et al., Elevated vitamin E content improves all-trans $\beta$-carotene accumulation and stability in biofortified sorghum, Proc. Natl. Acad. Sci. U. S. A., 113 (2016) 11040-11045.

[255] R.K. Saini, S.H. Nile, S.W. Park, Carotenoids from fruits and vegetables: Chemistry, analysis, occurrence, bioavailability and biological activities, Food Res. Int., 76 (2015) 735-750.

[256] M.R. La Frano, F.F. de Moura, E. Boy, B. Lönnerdal, B.J. Burri, Bioavailability of iron, zinc, and provitamin A carotenoids in biofortified staple crops, Nutr. Rev., 72 (2014) 289-307.

[257] M.J. Haskell, The challenge to reach nutritional adequacy for vitamin A: $\beta$-carotene bioavailability and conversion — evidence in humans, Am. J. Clin. Nutr., 96 (2012) 1193S-1203S.

[258] B.M. Swamy, M. Samia, R. Boncodin, S. Marundan, D.B. Rebong, R.L. Ordonio, et al., Compositional Analysis of Genetically Engineered GR2E "Golden Rice" in Comparison to That of Conventional Rice, J. Agric. Food Chem., 67 (2019) 7986.

[259] J.W. Low, M. Arimond, N. Osman, B. Cunguara, F. Zano, D. Tschirley, A food-based approach introducing orange-fleshed sweet potatoes increased vitamin A intake and serum retinol concentrations in young children in rural Mozambique, J. Nutr., 137 (2007) 1320-1327.

[260] M.J. Haskell, K.M. Jamil, F. Hassan, J.M. Peerson, M.I. Hossain, G.J. Fuchs, K.H. Brown, 
Daily consumption of Indian spinach (Basella alba) or sweet potatoes has a positive effect on total-body vitamin A stores in Bangladeshi men, Am. J. Clin. Nutr., 80 (2004) 705-714.

[261] A.C. Palmer, K. Healy, M.A. Barffour, W. Siamusantu, J. Chileshe, K.J. Schulze, et al., Provitamin A carotenoid-biofortified maize consumption increases pupillary responsiveness among Zambian children in a randomized controlled trial, J. Nutr., 146 (2016) 2551-2558.

[262] C. Zhu, G. Farré, D. Zanga, J. Lloveras, A. Michelena, J. Ferrio, et al., High-carotenoid maize: development of plant biotechnology prototypes for human and animal health and nutrition, Phytochem Rev., 17 (2018) 195-209.

[263] C. Nogareda, J.A. Moreno, E. Angulo, G. Sandmann, M. Portero, T. Capell, et al., Carotenoid-enriched transgenic corn delivers bioavailable carotenoids to poultry and protects them against coccidiosis, Plant Biotechnol. J., 14 (2016) 160-168.

[264] J.G. Schaart, C.C. van de Wiel, L.A. Lotz, M.J. Smulders, Opportunities for products of new plant breeding techniques, Trends. Plant. Sci., 21 (2016) 438-449.

[265] V. Nekrasov, C. Wang, J. Win, C. Lanz, D. Weigel, S. Kamoun, Rapid generation of a transgene-free powdery mildew resistant tomato by genome deletion, Sci. Rep., 7 (2017) 482.

[266] Z. Shimatani, S. Kashojiya, M. Takayama, R. Terada, T. Arazoe, H. Ishii, et al., Targeted base editing in rice and tomato using a CRISPR-Cas9 cytidine deaminase fusion, Nat. Biotechnol., 35 (2017) 441.

[267] Y. Zhang, Z. Liang, Y. Zong, Y. Wang, J. Liu, K. Chen, et al., Efficient and transgene-free genome editing in wheat through transient expression of CRISPR/Cas9 DNA or RNA, Nat. Commun., 7 (2016) 12617.

[268] E.C. Tatsis, S.E. O’Connor, New developments in engineering plant metabolic pathways, Curr. Opin. Biotechnol., 42 (2016) 126-132.

[269] K. Belhaj, A. Chaparro-Garcia, S. Kamoun, V. Nekrasov, Plant genome editing made easy: targeted mutagenesis in model and crop plants using the CRISPR/Cas system, Plant methods, 9 (2013) 39.

[270] X. Li, Y. Wang, S. Chen, H. Tian, D. Fu, B. Zhu, et al., Lycopene is enriched in tomato fruit by CRISPR/Cas9-mediated multiplex genome editing, Front. Plant Sci., 9 (2018) 559.

[271] D. Liu, R. Hu, K.J. Palla, G.A. Tuskan, X. Yang, Advances and perspectives on the use of CRISPR/Cas9 systems in plant genomics research, Curr. Opin. Biotechnol., 30 (2016) 70-77.

[272] M. Nogueira, E.M. Enfissi, M.E.M. Valenzuela, G.N. Menard, R.L. Driller, P.J. Eastmond, et al., Engineering of tomato for the sustainable production of ketocarotenoids and its evaluation in aquaculture feed, Proceedings of the National Academy of Sciences, 114 (2017) 10876-10881. 
[273] A.J. Simkin, J. Gaffé, J.-P. Alcaraz, J.-P. Carde, P.M. Bramley, P.D. Fraser, M. Kuntz, Fibrillin influence on plastid ultrastructure and pigment content in tomato fruit, Phytochemistry, 68 (2007) 1545-1556.

[274] J.-C. Huang, Y.-J. Zhong, J. Liu, G. Sandmann, F. Chen, Metabolic engineering of tomato for high-yield production of astaxanthin, Metab. Eng., 17 (2013) 59-67.

[275] L. Giliberto, G. Perrotta, P. Pallara, J.L. Weller, P.D. Fraser, P.M. Bramley, et al., Manipulation of the blue light photoreceptor cryptochrome 2 in tomato affects vegetative development, flowering time, and fruit antioxidant content, Plant Physiol, 137 (2005) 199-208.

[276] Y. Liu, S. Roof, Z. Ye, C. Barry, A. Van Tuinen, J. Vrebalov, et al., Manipulation of light signal transduction as a means of modifying fruit nutritional quality in tomato, Proc. Natl. Acad. Sci. U. S. A., 101 (2004) 9897-9902.

[277] S. Römer, P.D. Fraser, J.W. Kiano, C.A. Shipton, N. Misawa, W. Schuch, P.M. Bramley, Elevation of the provitamin A content of transgenic tomato plants, Nat. Biotechnol., 18 (2000) 666.

[278] S. Dharmapuri, C. Rosati, P. Pallara, R. Aquilani, F. Bouvier, B. Camara, G. Giuliano, Metabolic engineering of xanthophyll content in tomato fruits, FEBS Lett., 519 (2002) 30-34.

[279] C. D’Ambrosio, G. Giorio, I. Marino, A. Merendino, A. Petrozza, L. Salfi, et al., Virtually complete conversion of lycopene into $\beta$-carotene in fruits of tomato plants transformed with the tomato lycopene $\beta$-cyclase (tlcy-b) cDNA, Plant Sci., 166 (2004) 207-214.

[280] M. Nogueira, L. Mora, E.M. Enfissi, P.M. Bramley, P.D. Fraser, Subchromoplast sequestration of carotenoids affects regulatory mechanisms in tomato lines expressing different carotenoid gene combinations, Plant Cell, 25 (2013) 4560-4579.

[281] Z. Luo, J. Zhang, J. Li, C. Yang, T. Wang, B. Ouyang, et al., A STAY-GREEN protein SISGR1 regulates lycopene and $\beta$-carotene accumulation by interacting directly with SIPSY1 during ripening processes in tomato, New Phytol, 198 (2013) 442-452.

[282] E.M. Enfissi, M. Nogueira, C. D'Ambrosio, A.L. Stigliani, G. Giorio, N. Misawa, P.D. Fraser, The road to astaxanthin production in tomato fruit reveals plastid and metabolic adaptation resulting in an unintended high lycopene genotype with delayed over-ripening properties, Plant Biotechnol. J., 17 (2019) 1501-1513.

[283] L. Liu, C. Jia, M. Zhang, D. Chen, S. Chen, R. Guo, et al., Ectopic expression of a BZR1$1 D$ transcription factor in brassinosteroid signalling enhances carotenoid accumulation and fruit quality attributes in tomato, Plant Biotechnol. J., 12 (2014) 105-115.

[284] C. Bai, T. Capell, J. Berman, V. Medina, G. Sandmann, P. Christou, C. Zhu, Bottlenecks in carotenoid biosynthesis and accumulation in rice endosperm are influenced by the precursorproduct balance, Plant Biotechnol. J., 14 (2016) 195-205. 
[285] C. Bai, J. Berman, G. Farre, T. Capell, G. Sandmann, P. Christou, C. Zhu, Reconstruction of the astaxanthin biosynthesis pathway in rice endosperm reveals a metabolic bottleneck at the level of endogenous $\beta$-carotene hydroxylase activity, Transgenic Res., 26 (2017) 13-23.

[286] T. Gerjets, G. Sandmann, Ketocarotenoid formation in transgenic potato, J. Exp. Biol., 57 (2006) 3639-3645.

[287] W.L. Morris, L.J. Ducreux, P.D. Fraser, S. Millam, M.A. Taylor, Engineering ketocarotenoid biosynthesis in potato tubers, Metab. Eng., 8 (2006) 253-263.

[288] R. Campbell, W.L. Morris, C.L. Mortimer, N. Misawa, L.J. Ducreux, J.A. Morris, et al., Optimising ketocarotenoid production in potato tubers: effect of genetic background, transgene combinations and environment, Plant Sci., 234 (2015) 27-37.

[289] L.J. Ducreux, W.L. Morris, P.E. Hedley, T. Shepherd, H.V. Davies, S. Millam, M.A. Taylor, Metabolic engineering of high carotenoid potato tubers containing enhanced levels of $\beta$-carotene and lutein, J. Exp. Biol., 56 (2004) 81-89.

[290] G. Diretto, S. Al-Babili, R. Tavazza, F. Scossa, V. Papacchioli, M. Migliore, et al., Transcriptional-metabolic networks in $\beta$-carotene-enriched potato tubers: the long and winding road to the Golden phenotype, Plant Physiol, 154 (2010) 899-912.

[291] G. Diretto, R. Welsch, R. Tavazza, F. Mourgues, D. Pizzichini, P. Beyer, G. Giuliano, Silencing of beta-carotene hydroxylase increases total carotenoid and beta-carotene levels in potato tubers, BMC Plant Biol., 7 (2007) 11.

[292] J. Van Eck, B. Conlin, D. Garvin, H. Mason, D. Navarre, C. Brown, Enhancing beta-carotene content in potato by RNAi-mediated silencing of the beta-carotene hydroxylase gene, Am. J. Potato Res., 84 (2007) 331.

[293] Y.-M. Goo, E.-H. Han, J.C. Jeong, S.-S. Kwak, J. Yu, Y.-H. Kim, et al., Overexpression of the sweet potato $\mathrm{IbOr}$ gene results in the increased accumulation of carotenoid and confers tolerance to environmental stresses in transgenic potato, C. R. Biol., 338 (2015) 12-20.

[294] G. Farré, S. Maiam Rivera, R. Alves, E. Vilaprinyo, A. Sorribas, R. Canela, et al., Targeted transcriptomic and metabolic profiling reveals temporal bottlenecks in the maize carotenoid pathway that may be addressed by multigene engineering, Plant J, 75 (2013) 441-455.

[295] S. Naqvi, C. Zhu, G. Farre, K. Ramessar, L. Bassie, J. Breitenbach, et al., Transgenic multivitamin corn through biofortification of endosperm with three vitamins representing three distinct metabolic pathways, Proc. Natl. Acad. Sci. U. S. A., 106 (2009) 7762-7767.

[296] T.E. Lipkie, F.F. De Moura, Z.-Y. Zhao, M.C. Albertsen, P. Che, K. Glassman, M.G. Ferruzzi, Bioaccessibility of carotenoids from transgenic provitamin A biofortified sorghum, J. Agric. Food Chem., 61 (2013) 5764-5771. 
[297] M.-J. Kim, J.K. Kim, H.J. Kim, J.H. Pak, J.-H. Lee, D.-H. Kim, et al., Genetic modification of the soybean to enhance the $\beta$-carotene content through seed-specific expression, PLoS One, 7 (2012) e48287.

[298] E.C. Pierce, P.R. LaFayette, M.A. Ortega, B.L. Joyce, D.A. Kopsell, W.A. Parrott, Ketocarotenoid production in soybean seeds through metabolic engineering, PloS one, 10 (2015) e0138196.

[299] J. Jayaraj, R. Devlin, Z. Punja, Metabolic engineering of novel ketocarotenoid production in carrot plants, Transgenic Res., 17 (2008) 489-501.

[300] P. Azadi, N.V. Otang, D.P. Chin, I. Nakamura, M. Fujisawa, H. Harada, et al., Metabolic engineering of Lilium $\times$ formolongi using multiple genes of the carotenoid biosynthesis pathway, Plant Biotechnol. J., 4 (2010) 269-280.

[301] S. Suzuki, M. Nishihara, T. Nakatsuka, N. Misawa, I. Ogiwara, S. Yamamura, Flower color alteration in Lotus japonicus by modification of the carotenoid biosynthetic pathway, Plant Cell Rep., 26 (2007) 951-959.

[302] S.-C. Park, S.H. Kim, S. Park, H.-U. Lee, J.S. Lee, W.S. Park, et al., Enhanced accumulation of carotenoids in sweetpotato plants overexpressing IbOr-Ins gene in purple-fleshed sweetpotato cultivar, Plant. Physiol. Biochem., 86 (2015) 82-90.

[303] T. Götz, G. Sandmann, S. Römer, Expression of a bacterial carotene hydroxylase gene (crtZ) enhances UV tolerance in tobacco, Plant Mol. Biol., 50 (2002) 127-140.

[304] V. Mann, M. Harker, I. Pecker, J. Hirschberg, Metabolic engineering of astaxanthin production in tobacco flowers, Nat. Biotechnol., 18 (2000) 888.

[305] T. Gerjets, M. Sandmann, C. Zhu, G. Sandmann, Metabolic engineering of ketocarotenoid biosynthesis in leaves and flowers of tobacco species, Biotechnol. J., 2 (2007) 1263-1269.

[306] C. Zhu, T. Gerjets, G. Sandmann, Nicotiana glauca engineered for the production of ketocarotenoids in flowers and leaves by expressing the cyanobacterial $\operatorname{crt} O$ ketolase gene, Transgenic Res., 16 (2007) 813-821.

[307] C.L. Mortimer, N. Misawa, L. Perez-Fons, F.P. Robertson, H. Harada, P.M. Bramley, P.D. Fraser, The formation and sequestration of nonendogenous ketocarotenoids in transgenic Nicotiana glauca, Plant Physiol, 173 (2017) 1617-1635.

[308] D. Wurbs, S. Ruf, R. Bock, Contained metabolic engineering in tomatoes by expression of carotenoid biosynthesis genes from the plastid genome, Plant J, 49 (2007) 276-288.

[309] W. Apel, R. Bock, Enhancement of carotenoid biosynthesis in transplastomic tomatoes by induced lycopene-to-provitamin A conversion, Plant Physiol, 151 (2009) 59-66. 
[310] K. Shindo, T. Hasunuma, E. Asagi, A. Sano, E. Hotta, N. Minemura, et al., 4-Ketoantheraxanthin, a novel carotenoid produced by the combination of the bacterial enzyme $\beta$-carotene ketolase $\mathrm{CrtW}$ and endogenous carotenoid biosynthetic enzymes in higher plants, Tetrahedron Lett., 49 (2008) 3294-3296. 
Declaration of competing interest

The authors declare that they have no known competing financial interests or personal relationships that could have appeared to influence the work reported in this paper. 